\title{
Evaluation of the properties of Toronto iron water mains and surrounding soil
}

\author{
Michael V. Seica, J effrey A. Packer, M.W.F. Grabinsky, and Barry J. Adams
}

\begin{abstract}
The problem of ageing water pipes manifesting leaks and breaks is common to municipalities throughout Canada, North America, and the world. Among them, the City of Toronto has been confronted with water main infrastructure problems, currently encountering a break rate of roughly two occurrences per week over a network of $5347 \mathrm{~km}$. The appropriate corrective action, which aims to restore pipe integrity and prevent future breaks and leaks, should be decided based on a general knowledge of the state of deterioration of the water main network, a thorough understanding of the governing failure modes, and a clear identification of the problem areas. To achieve these goals, an extensive sampling and testing programme was undertaken by the University of Toronto in collaboration with the City of Toronto. The programme encompassed a period of three years, from 1998 to 2000, and involved the testing and analysis of 100 exhumed pipe samples, mostly cast iron, in the University's structural testing laboratories. The purpose of these tests was to ascertain the extent of material loss due to corrosion, the mechanical properties of the pipe material, and the mode of failure. Simultaneously, soil samples were extracted in the proximity of the sampled pipes, identified, and classified, and their corrosion aggressiveness was investigated through tests in the University's environmental and geotechnical engineering laboratories. The outcome of this interdisciplinary investigation, complemented by further research efforts, should lead to a clearer understanding of water main failure phenomena and contribute to the efforts of the many cities endeavouring to minimize the number of break occurrences and prioritize their maintenance and rehabilitation schedules.
\end{abstract}

Key words: water mains, pipes, infrastructure, cast iron, ductile iron, corrosion, mechanical properties, soil properties, site sampling.

Résumé : Le problème des conduites d'eau vieillissantes, lieu de fuites ou de ruptures, est commun à travers les municipalités du Canada, de l'Amérique du Nord et du monde. Parmi elles, la Ville de Toronto a été confrontée à des problèmes d'infrastructure de ses conduites d'eau et enregistre actuellement une fréquence de rupture d'environ deux fois par semaine pour un réseau long de $5347 \mathrm{~km}$. Une intervention appropriée, consistant en la restauration de l'intégrité des conduites et en la prévention des fuites et ruptures à venir, devrait s'appuyer sur une connaissance générale de l'état de détérioration du réseau de conduite d'eau, sur une compréhension approfondie des modes de rupture principaux, et sur une identification claire du domaine qui pose problème. Pour ce faire, un vaste programme d'échantillonnage et de test a été entrepris par l'Université de Toronto en collaboration avec la Ville de Toronto. Le programme a couvert une période de trois ans, de 1998 à 2000, et a impliqué le test et l'analyse de 100 échantillons de conduite sortis de terre, principalement en fonte, au sein des laboratoires de test de structures de l'Université. Le but de ces tests était d'établir l'étendue de la perte en matériau due à la corrosion, les propriétés mécaniques du matériau de la conduite et le mode de rupture. En même temps, des échantillons de sol ont été prélevés à proximité des conduites ayant servi à l'échantillonnage; ils ont été identifiés et classés, et leur agressivité en tant que corrosif a été étudiée au travers de tests réalisés dans les laboratoires de génie environnemental et géotechnique. Les résultats de cette enquête interdisciplinaire, complétée par des efforts de recherche ultérieurs, devrait déboucher sur une meilleure compréhension des phénomènes de rupture des conduites d'eau et venir en aide aux nombreuses villes qui s'efforcent de minimiser la fréquence des ruptures et de gérer au mieux leurs programmes de maintenance et de réhabilitation.

Mots clés : conduites d'eau, tuyaux, infrastructure, fonte, fonte ductile, corrosion, propriétés mécaniques, propriétés du sol, échantillonnage du site.

[Traduit par la Rédaction]

Received 1 May 2001. Revised manuscript accepted 3 December 2001. Published on the NRC Research Press Web site at http://cjee.nrc.ca on 19 March 2002.

M.V. Seica, ${ }^{1}$ J.A. Packer, M.W.F. Grabinsky, and B.J. Adams. Department of Civil Engineering, University of Toronto, 35 St. George Street, Toronto, ON M5S 1A4, Canada.

Written discussion of this article is welcomed and will be received by the Editor until 31 August 2002.

${ }^{1}$ Corresponding author (e-mail: seica@civ.utoronto.ca). 


\section{Introduction}

The provision of an adequate quantity and quality of water has been a matter of concern since the beginning of civilization. In ancient cities, local supplies were often inadequate and aqueducts were built to convey water from distant sources. Such supply systems did not distribute water to individual residences, but rather brought it to a few central locations from which the citizens could carry it to their homes.

Until the middle of the seventeenth century, pipes that could withstand significant pressures were not available. Pipes made of wood, clay, or lead were used, but generally laid at the hydraulic grade line. The development of cast iron pipe and the gradual reduction in its cost, together with the development of improved pumps driven by steam, made it possible for even small communities to provide public supplies and deliver the water to individual residences (McGhee 1991).

This led to the extensive use of cast iron pipes from the end of the last century until the late 1960s when they yielded their supremacy to ductile iron pipes. More recently, plastic PVC pipes have grown in preference as candidates for this type of application.

Initially, the first cast iron pipes used were manufactured using the pit casting method, whilst later on this process was replaced by centrifugal casting technology. At present, all new iron pipes installed are made of ductile iron and cast using a technology similar to the cast iron centrifugal casting method.

The old, predominantly cast iron water distribution systems, including the one servicing the Toronto area, have aged considerably and show signs of deterioration mainly in the form of breaks and leaks that require attention ever more often.

\section{Overview}

The problems with which the City of Toronto has been acutely confronted, namely the leaking and breaking of aged pipes and system repair, are not confined to the Toronto area. Rather, these issues are common throughout Canada, North America, and the world. Ontario alone is estimated to have $200000 \mathrm{~km}$ of water mains and sewage pipelines (ES\&E 1997), many of which are in urgent need of repair or replacement (Davey 1997; Crawford 1996). Moreover, a survey by the U.S. Environment Protection Agency estimated that $\$ 138$ billion must be invested in water systems over the next 20 years, a significant proportion of which must go into distribution systems (Hertzler and Davies 1997).

One of the most chronic and worrisome aspects of a deteriorated water distribution system is the water lost through leaky pipes. Since leaks often account for $10 \%$ to $30 \%$ of the total water supplied, they can represent a significant waste. Leaks can also be a point of entry of contaminants into the pipeline. In addition, losses due to leaks mean that more water is required by the distribution system, hence requiring larger storage reservoirs, treatment facilities, pipelines, pumps, and energy costs (Keeling 1996; Karney 1996). However, with the growing awareness of the problem has come a growing determination to take corrective action based on more complete data on the state of water distribution systems.

Although the mechanisms of failure are not yet fully understood, it is widely assumed that one of the main causes of pipe deterioration leading to failure is corrosion induced by a harsh surrounding environment, both external and internal to the pipe. Several coatings that avoid direct contact between soil and (or) water and the pipe have been developed, but corrosion, although much diminished by these coatings, still takes place. It occurs most commonly in the form of "graphitic corrosion" (or graphitization) in the case of cast iron, whereby the iron is leached out of the material, leaving behind the graphite matrix intact. Hence, corrosion pits develop, but they may not be readily distinguishable since the remaining carbon network has the tendency to keep the original shape of the pipe, whilst having a structural resistance much smaller than that of the original material.

Ductile iron corrodes in the form of distinct, readily noticeable corrosion pits. Since both cast and ductile iron develop corrosion pits, the former disguised by graphitization, the effect on the overall mechanical resistance of the pipe is basically the same for both materials.

\section{Objectives and significance of a testing programme}

The present interdisciplinary research effort addresses the need for a more complete, diversified, and comprehensive database related to the deterioration, breakage, and material condition of water mains under the jurisdiction of the City of Toronto. The main goal is to quantitatively determine both the extent of the deterioration of each pipe sample and the probable mechanisms that were responsible for this condition. To achieve this, specific objectives have been set and these are to

- establish the geometrical properties of cast iron pipes to verify compliance with standard specifications and identify defects that were a direct or indirect result of corrosion;

- determine the mechanical properties of cast iron pipes using different test methods with the intent of identifying the most pertinent test method for the problem in question;

- perform general and specific soil tests to estimate the corrosion potential of the surrounding soil as well as its susceptibility to apply mechanical actions on the pipe; and

- correlate all test data and identify the most probable mechanism responsible for pipe failure.

Water utilities often base their repair/replacement criteria on past experience using a cost efficiency indicator that relies on the number of breaks that have occurred within a certain length of the pipe (usually one kilometre) during a certain period of time (usually one year) without taking into account specific local conditions that may have led to failure. Thus, the principal benefits of studying the causes of failure in the framework of this testing programme are the following:

- minimization of the number and severity of break occurrences, which leads to improved customer service;

- a priority schedule for pipe repair or replacement; and

- assessment of the impact of corrosion and other phenomena that lead to deterioration of the structural resistance of the pipes. 
Other recent research efforts (Rajani and Makar 2000) focused on the development of methods to estimate the remaining service life of cast iron pipes in an attempt to predict the "best" time to replace a pipe segment before failure occurs. But, unlike this study which focused on cast iron pipes sampled only from within the boundaries of the city of Toronto, their work was based on analysing 66 pipe samples and 61 soil samples which had originated from as many as 15 different municipalities across North America (Rajani et al. 2000) and were, therefore, not representative of a specific region. It is well understood that without in-depth knowledge about the state of deterioration of a water distribution system across an entire network, the use and benefits of such predictive methods become limited.

\section{Testing programme}

Like many other utilities, the City of Toronto has been confronted with a continuous deterioration of its water distribution network. The average age of the system in the former City of Toronto area is 90 years, and it encounters approximately two water pipe breaks per week. Most of the pipes in this system range between 100 and $300 \mathrm{~mm}$ (4 to 12 in.) in diameter and are made of grey cast iron, although some newer pipes are manufactured from ductile cast iron (Dennis 1998).

As mentioned previously, one of the leading causes of pipe failure is the structural weakening of the pipe wall as a result of corrosion. Corrosive agents in the surrounding soil attack the pipe metal from the outside, whilst other aggressive chemical components produce a similar effect on the inside surface of the pipe. The latter phenomenon can easily be counteracted to a certain extent by "lining" the pipe (e.g., applying a protective cement-mortar layer on the internal surface of the pipe wall), which prevents direct contact between the water's corrosive chemical constituents and the cast iron material. Another important benefit resulting from lining is that drastic reductions of the cross-sectional area of the pipes, which occur as a result of "tuberculation" (a secondary product of corrosion which forms at the interface between water and metal), are prevented. A typical reduction in the available cross-sectional area can be seen in Fig. 1, which illustrates a heavily tuberculated cast iron pipe.

There are several typical structural failure modes that have been observed in the sample of Toronto cast iron water mains. Pipes can fail by cracking either circumferentially or longitudinally, may exhibit corrosion holes or leak at the joints, or can experience a combination of these modes. Figure 2 shows, from top, a circumferentially cracked and clamped $150 \mathrm{~mm}$ pipe, a circumferentially cracked $150 \mathrm{~mm}$ pipe as well as a longitudinally cracked $200 \mathrm{~mm}$ pipe. Stainless steel clamps are normally used either for the repair of minor circumferential cracks or small holes, or to delay the actual pipe segment replacement and to temporarily restore the water supply service.

\section{Pipe and soil sampling protocol}

To ensure accuracy, relevance, and completeness of data, of both that directly received from the site and the resulting information after tests had been conducted, specialists from the Works Department of the City of Toronto met several
Fig. 1. Severe tuberculation drastically reducing the effective cross-sectional area of a pipe.

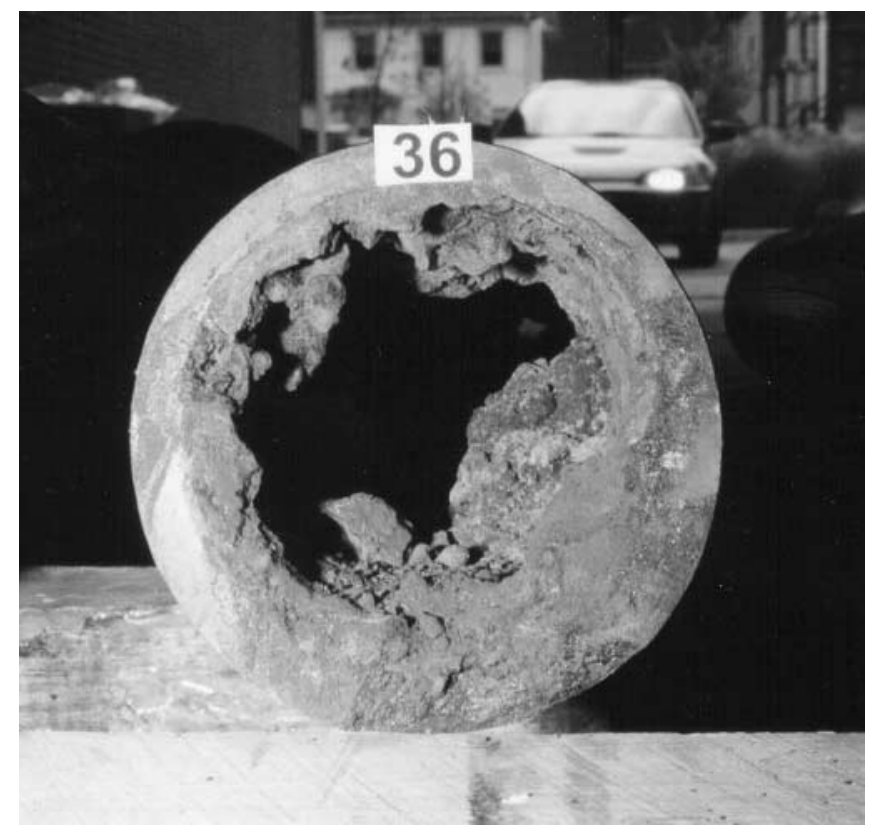

Fig. 2. Circumferentially cracked, longitudinally cracked, and clamped pipes.

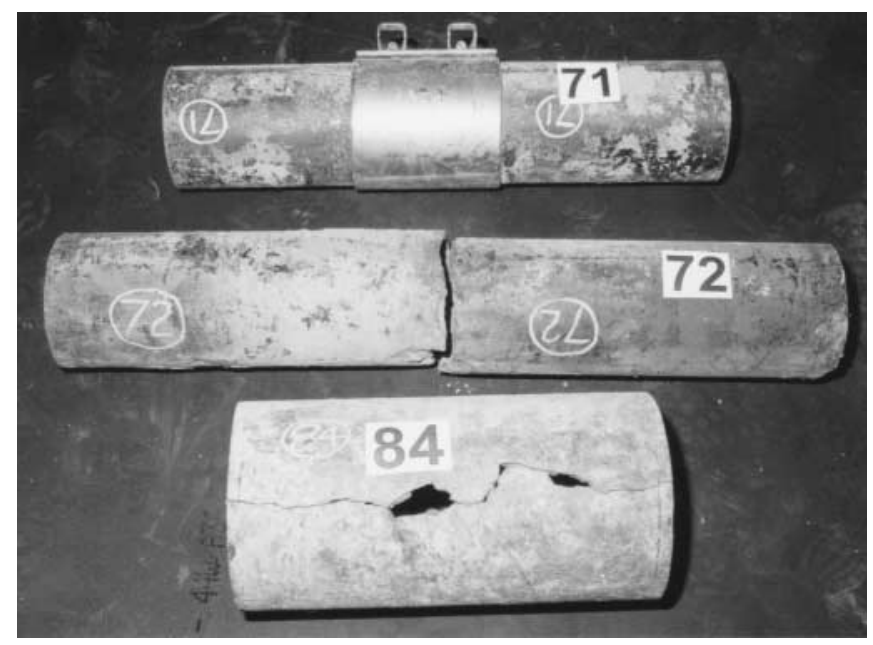

times with researchers from the Department of Civil Engineering at the University of Toronto. These discussions led to the development of a "Pipe and Soil Sampling Procedures Protocol" which fully and completely stipulated all the requirements and actions to be taken during sample collection.

Consequently, City of Toronto personnel were instructed to exhume and deliver pipe and soil samples either whenever a break occurred or following scheduled maintenance repairs of the water mains. Specific and detailed instructions referring to how to exhume, cut, label, and preserve the pipes before delivery to the University of Toronto laboratories were issued. Similar instructions were elaborated for the soil sampling procedures with emphasis on specific measures to be taken to preserve the soil properties and avoid contamination.

A crucial part of the protocol was the "Pipe and Soil Sample Field Report". This is a form that must be completed 
with relevant information about the location, pipe environment, type of pipe, and mode of failure, as well as the history of the pipe, and must be filled in completely by both the crew foreman and a City Works engineer.

In spite of the careful planning of the sampling procedures and all precautionary measures taken, which also involved a number of meetings with City foremen and work crews, a few sampling problems were encountered, increasing the risk of altering certain material properties. Other organizational problems also arose; however, such occurrences are difficult to avoid in the framework of such a complex project involving the participation of a large number of people in the sampling process.

\section{Tests on pipes}

To determine the structural state of the pipes and the prevalent cause of pipe failure, several tests were conducted. Each of them gave particular results on specific material properties and all were performed in accordance with ASTM and ASA standards as explained below.

\section{Geometrical evaluation}

The main purpose of this test was to characterize the general state of the pipes. Material flaws originating from manufacture, the wall thickness and diameter compliance with appropriate standard specifications, the amount of metallic material lost to corrosion, and the size and distribution of corrosion pits were all determined through geometrical measurements.

Upon receipt, each pipe underwent a preliminary cleaning, followed by a visual inspection. A ring having a length of $150 \mathrm{~mm}$ was then cut from the pipe and further cleaned. The purpose of this cleaning was the removal of all dirt, tubercles, and lining materials, if any, leaving the pipe somewhat similar to when it had left the foundry. This was followed by a first set of measurements of the external diameter and thickness, which were performed at six points around the circumference of the ring and at each end, producing a total of 24 measurements. These results could be compared to standard values given in ASA A21.2 (1962), ASA A21.6 (1962), and ASA A21.8 (1962). As well, by averaging the thickness and diameters, the volume of the ring was determined and, by knowing the density of cast iron, the assumed initial (before installation) mass of the ring was computed.

After the first set of measurements, the ring was sandblasted in order to remove all corrosion products, principally the graphite matrix that remained after the iron had been leached during the graphitization process. Care was taken during sandblasting in order not to "over-blast", as the metal itself is not immune to sandblasting and layers of metal may be removed, giving a false indication of reduced wall thickness.

Again, the rings underwent another similar set of wall thickness measurements, 12 in total, which evaluated the type and severity of corrosion phenomena. Altogether, 36 measurements were performed both before and after the sandblasting operation and all measurements were performed with callipers capable of $0.1 \mathrm{~mm}$ accuracy. The rings were then accurately weighed and this value, subtracted from the "as new" estimated weight, gave a reasonable esti- mate of the amount of metal lost to corrosion. A more accurate measurement of corrosion pits was also performed in conformity with the ASTM G46-94 (1994) standard, since a further evaluation of their degree of corrosion was deemed necessary.

\section{Tensile test}

Testing was performed on specimens that had been removed from the pipe "as is", before undergoing any aggressive cleaning process such as sandblasting, i.e., including all corrosion products such as graphitization. Therefore, information about the behaviour of the pipe in its current in situ state was obtained.

Tests were performed on "dog-bone" shaped specimens manufactured to ASTM E8-94a (1994) specifications and sampled at random around the circumference of the pipe. One test was performed on each pipe sample, but it was well understood that the results thus obtained might not always be completely representative, given the variability of many factors affecting the properties of aged pipes. For the purpose of this project and given the existing testing equipment, "Specimen 1" type was selected, having a gauge length of $50 \mathrm{~mm}$ and a width of $12.5 \mathrm{~mm}$. The thickness of the specimen was the same as the wall thickness of the pipe. Because of the curvature of the grip sections of the specimens and in order to avoid cracking them under high gripping pressure, a special set of curved grips was manufactured in accordance with the ASTM specifications. The tests were carried out using an MTS universal testing machine under controlled displacement conditions at a displacement rate of $20 \mathrm{~mm}$ per $3200 \mathrm{~s}$ and the load-strain curve was automatically recorded.

After testing, the fracture surfaces were macrophotographed and then the broken specimens underwent sandblasting to remove the dirt, pipe coatings, and all the corrosion products, but not metal. A new set of photographs of the fractured surfaces were then taken. All photographs were again magnified on a copy machine and exact contour replicas of the fractured surfaces were afterwards cut from plain white paper. By determining the paper density, the magnification scale, and the accurate weight of the paper surface replicas, the specimen cross-sectional area at the point of fracture both before and after sandblasting was computed. By then dividing the load by the total area, an "apparent" ultimate tensile stress (i.e., the pipe strength "as is") could be calculated, whilst by using the net metallic area an "effective" ultimate tensile stress (i.e., the cast iron strength) was obtained, and hence the loss of strength was also computed.

Besides stress-strain relationships, the Young's modulus of elasticity was computed for each pipe sample. Two moduli were determined: the initial tangent modulus and the secant modulus corresponding to the point of failure. The latter is simply the slope of a line from the origin to the point of highest stress on the stress-strain curve, whilst the former is the slope of a line that is tangent to the stressstrain curve at the point of origin.

\section{Ring bearing test}

The main stresses in the pipes arise from the inside water pressure and from the outside earth and overburden load. The first case may be accounted for by means of a bursting 
Fig. 3. Typical ring bearing test setup.

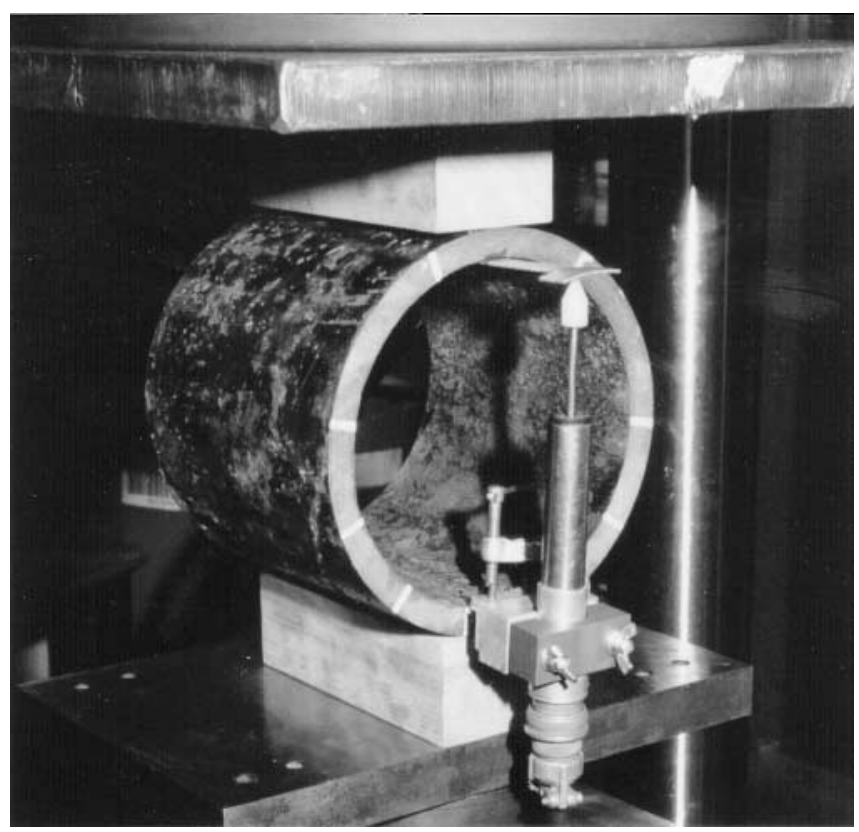

tensile test, which can be done on a segment of pipe that has been capped at both ends, as specified by ASA A21.6 and ASA A21.8 (1962). Water under pressure is introduced inside and the pressure is increased until failure (break of the pipe) takes place. Alternatively, the tensile strength can be obtained through tensile tests on coupons, as described herein.

Secondly, an indication of the pipe strength with respect to external loads is given by the rupture modulus. This is a characteristic of the pipe material that shows its ability to resist bending stresses. The rupture modulus may be calculated from a ring bearing test using the following relationship (ASA A21.6 and ASA A21.8 1962), expressed in SI units

$$
R=954 \frac{W(d+t)}{b t^{2}}
$$

where $R$ is the rupture modulus ( $\mathrm{MPa}), W$ is the "breaking" load $(\mathrm{kN}), d$ is the average inside diameter $(\mathrm{mm}), t$ is the average thickness of the pipe along the principal line of fracture $(\mathrm{mm})$, and $b$ is the length of the ring $(\mathrm{mm})$.

The test simulates the vertical gravitational action of the soil above the pipe and is rather conservative in the sense that it does not account for the pipe-soil interaction effects that occur at other angles.

In accordance with ASA A21.6 and ASA A21.8 (1962), pipe rings with a length of a minimum of one-half of the nominal diameter of the pipe and a maximum of $300 \mathrm{~mm}$ were loaded in compression to failure, between two bearing plates, in a three-point loading system. In addition to the provisions of the standards, the ring was also fitted with a linearly varying displacement transducer (LVDT), mounted vertically (i.e., parallel to the direction of the applied load) and held in place by a pair of clamps that were attached to the inside surface of the pipe. A typical test setup is presented in Fig. 3. During the tests, load-displacement curves were recorded. The rings were tested before any cleaning ac- tion took place to ensure that the obtained values were representative for the pipe in its existing state.

\section{Soil tests}

As explained, tests were performed on pipes to establish the physical and mechanical properties of cast iron. These data would not have been complete unless tests on neighbouring soils had also been conducted. These tests help to determine the nature of the soil in which the pipes had been laid, emphasizing important properties with respect to physical and chemical aspects of material behaviour. These data, in turn, present information needed to assess the contribution of the soil characteristics, such as chemical aggressiveness, to the failure of the pipe.

Underground corrosion is primarily promoted by the presence of moisture and oxygen, redox potential, $\mathrm{pH}$, soil resistivity, and microbial activity (METALogic 1998). To assess the soil aggressiveness, four different soil testing procedures were established, namely, description and identification of soils, resistivity measurement, $\mathrm{pH}$ measurement, and sulphide test. The reasons for choosing them, together with a brief description of each, are explained below.

\section{Soil description and identification}

This test is in fact composed of a multitude of individual tests with the aim of providing a general classification of the soil samples. The identification is based on visual-manual procedures presented in detail in the ASTM D2488-93 (1993) standard, which provides standardized criteria and procedures for describing and identifying soils. There is a general test category - descriptive information of soils which contains items such as grain angularity and shape, colour, odour, moisture condition, and $\mathrm{HCl}$ reaction, as well as two specific categories that apply to the identification of fine-grained soils and coarse-grained soils, respectively. The fine-grained soil description includes properties such as dry strength, dilatency, toughness, plasticity, and identification of inorganic fine-grained soils, whilst the coarse-grained soil identification procedure classifies the material as gravel, sand, silt, or combinations of these. All identifying methods, which are thoroughly described in the standard, were used and are not reiterated here.

\section{Resistivity}

Soil contains, amongst a multitude of chemical elements and compounds, a great number of salts. These may have an unfavourable effect through increasing the corrosion rate of cast iron pipes by the creation of galvanic cells. One of the salts having the most devastating effects is sodium chloride, $\mathrm{NaCl}$, which, in Toronto urban environment soils, is abundantly present as a consequence of road de-icing practices.

Resistivity is the property of a conductive material to withstand electrical current, or, more precisely, it is the electrical resistance between the opposite faces of a unit cube of material. Moist soil, containing a variety of salts, behaves as an electrolyte, i.e., it has the ability to conduct current. The higher the concentration of salts in solution, the easier it is for soil to conduct current and, hence, it will be characterized by a lower value of resistivity. In other words, the lower the resistivity of the soil, the higher the corrosion potential. 
The chosen laboratory resistivity test was the Wenner four-electrode method as indicated in ASTM G57-95a (1995). The method is rather simple and uses a so-called soil box. The box, which accommodates a soil volume of $264 \mathrm{~cm}^{3}$, is equipped with four electrodes. A voltage is impressed between the outer electrodes, causing a current flow between them, and the voltage drop between the inner electrodes is measured using a sensitive digital voltmeter. Having measured the value of the current and knowing the geometrical dimensions of the box, the resistivity can be computed as

$$
\text { [2] } \rho=\frac{U}{I} \frac{A}{a}
$$

where $\rho$ is the soil resistivity $(\Omega \cdot \mathrm{cm}), U$ is the voltage drop between the inner electrodes $(\mathrm{V}), I$ is the current drawn from the source (A), $A$ is the cross-sectional area of the container, perpendicular to the current flow $\left(\mathrm{cm}^{2}\right)$, and $a$ is the inner electrode spacing measured from the inner edge of the electrode pins $(\mathrm{cm})$.

For a quick, practical estimate of the corrosiveness of the soils, the resistivity values alone are often considered. A classification of the aggressiveness of soils as a function of their resistivity is given in Table 1 (METALogic 1998).

\section{pH}

Depending on the principal corrosion agent responsible, a soil characterized by a certain hydrogen-ion density level would offer proper attack conditions.

A standard procedure used in this project to measure the $\mathrm{pH}$ of soils is described in ASTM G51-95 (1995). It makes use of a glass electrode in a dedicated instrument.

A small amount of soil, usually $10 \mathrm{~g}$, was mixed with distilled water into a slurry until all soluble chemicals were dissolved. After that, the $\mathrm{pH}$ electrode was immersed into the solution and the reading recorded after a few minutes, when the $\mathrm{pH}$ value reached equilibrium. All tests were done in a constant temperature environment to ensure consistency of results.

\section{Sulphide}

Microbiological corrosion might be an important component leading to cast iron pipe damage. As the name implies, aggressive sulphate-reducing bacteria metabolize sulphates into sulphides; hence, an easy way to test a soil for their presence is to test it for sulphide concentration.

There are several standardized test methods for sulphides, mainly used for waste water, but these are all cumbersome and time consuming and require expensive laboratory equipment. Therefore, another test method has been developed at the University of Toronto.

Ten grams of soil are mixed with $90 \mathrm{~mL}$ of distilled water inside a $500 \mathrm{~mL}$ flask until the soluble salts become dissolved into solution. During this operation, the flask's neck is sealed with cling film to avoid gas escape. Then, $5 \mathrm{~mL}$ of concentrated hydrochloric acid $(\mathrm{HCl})$ is added with the purpose of reacting with all sulphide salts and ions in the solution and transforming them into hydrogen sulphide $\left(\mathrm{H}_{2} \mathrm{~S}\right)$. The amount of hydrogen sulphide is measured using calibrated Gastec hydrogen sulphide detection safety tubes. These are glass vials that are attached to a calibrated pump
Table 1. Soil corrosiveness as a function of resistivity (METALogic 1998).

\begin{tabular}{lll}
\hline $\begin{array}{l}\text { Soil resistivity } \\
(\Omega \cdot \mathrm{cm})\end{array}$ & Types of soil & Expected corrosiveness \\
\hline$>20000$ & Sand & Virtually not aggressive \\
$10000-20000$ & Sand & Weakly aggressive \\
$5000-10000$ & Loam & Moderately aggressive \\
$3000-5000$ & Loam, peat & Aggressive \\
$1000-3000$ & Clay, peat & Strongly aggressive \\
$500-1000$ & Brackish, clay & Very strongly aggressive \\
$<500$ & Clay & Extremely aggressive \\
\hline
\end{tabular}

and are in contact with the atmosphere that requires testing, and these vials contain lead acetate powder inside and calibration lines outside. A certain amount of gas volume is passed through the tube with the aid of the pump and, if hydrogen sulphide is present, the white powder inside the tube changes colour to brown up to a certain level. This is the level of hydrogen sulphide present in the gaseous volume of the sealed flask and the value is read in parts per million (ppm) using the calibration lines. To convert this value into units of $\mathrm{mg} / \mathrm{kg}$ of dry mass of soil, the moisture content of the soil sample must be determined and the following relationship was developed and used (Seica et al. 2000):

[3] $\quad S^{2-}=0.0867(\mathrm{ppm})\left(\frac{w}{100}+1\right)$

where $S^{2-}$ is the concentration of sulphide in dry mass of soil $(\mathrm{mg} / \mathrm{kg})$, ppm is the parts per million measured sulphide value using a Gastec tube (ppm), and $w$ is the moisture content of soil $(\%)$.

Similar to other tests, all sulphide determinations were done under strict laboratory conditions, including constant temperature, as this is assumed in both the Ideal Gas Law and Henry's constant, which were used in the derivation of eq. [3].

\section{Test results}

For the purpose of this discussion, a "sample" denotes any water main site "souvenir" that was received from the City, whether it be a pipe, soil, or just a completed field report form, as well as any combination thereof (i.e., a sample can be a pipe sample and (or) a soil sample and (or) a filled-in report form). The individual samples are referred to as pipe samples or pipes, soil sample, and field report forms.

A total of 117 samples were received by the University from the various districts of Toronto. Out of these, 111 included pipe samples, of which 73 pipe samples were associated with pipe breaks, whilst the remaining 38 did not experience any major structural damage. The latter were removed during rehabilitation operations on existing pipes. The remaining six samples were either soil samples only (4 samples) or corresponded to instances when the University was delivered a field report form without any pipe or soil sample attached to it (2 samples).

The pipe sample diameters were in the range of 100 to $400 \mathrm{~mm}$ with most of the pipes being between 100 and $300 \mathrm{~mm}$ in diameter. The material was mostly grey cast iron, 
Table 2. Comparison between prescribed and measured geometrical properties of pipes (before sandblasting).

\begin{tabular}{|c|c|c|c|c|c|c|c|c|c|c|}
\hline \multirow{4}{*}{$\begin{array}{l}\text { Pipe } \\
\text { diameter } \\
(\mathrm{mm})\end{array}$} & \multirow[b]{4}{*}{ Range } & \multicolumn{6}{|c|}{ Thickness } & \multirow{2}{*}{\multicolumn{3}{|c|}{$\begin{array}{l}\text { Outside diameter } \\
\text { Both cast and ductile iron }\end{array}$}} \\
\hline & & \multicolumn{3}{|c|}{ Grey cast iron } & \multicolumn{3}{|c|}{ Ductile iron } & & & \\
\hline & & \multicolumn{2}{|c|}{ Prescribed } & \multirow{2}{*}{$\begin{array}{l}\text { Measured } \\
(\mathrm{mm})\end{array}$} & \multicolumn{2}{|c|}{ Prescribed } & \multirow{2}{*}{$\begin{array}{l}\text { Measured } \\
(\mathrm{mm})\end{array}$} & \multicolumn{2}{|c|}{ Prescribed } & \multirow{2}{*}{$\begin{array}{l}\text { Measured } \\
(\mathrm{mm})\end{array}$} \\
\hline & & (in.) & $(\mathrm{mm})$ & & (in.) & $(\mathrm{mm})$ & & (in.) & $(\mathrm{mm})$ & \\
\hline \multirow[t]{2}{*}{100} & Minimum & 0.35 & 8.9 & 9.9 & 0.29 & 7.4 & - & 4.8 & 121.9 & 119.7 \\
\hline & Maximum & 0.44 & 11.2 & 12.7 & 0.41 & 10.4 & - & 4.8 & 121.9 & 129.4 \\
\hline 150 & Maximum & 0.52 & 13.2 & 15.9 & 0.43 & 10.9 & 9.9 & 6.9 & 175.3 & 180.9 \\
\hline \multirow[t]{2}{*}{200} & Minimum & 0.41 & 10.4 & 11.1 & 0.33 & 8.4 & 7.6 & 9.05 & 229.9 & 229.0 \\
\hline & Maximum & 0.6 & 15.2 & 15.0 & 0.45 & 11.4 & 7.6 & 9.05 & 229.9 & 237.3 \\
\hline \multirow[t]{2}{*}{250} & Minimum & 0.44 & 11.2 & 11.6 & 0.35 & 8.9 & - & 11.1 & 281.9 & 282.6 \\
\hline & Maximum & 0.65 & 16.5 & 11.6 & 0.47 & 11.9 & - & 11.1 & 281.9 & 282.6 \\
\hline 300 & Minimum & 0.48 & 12.2 & 14.8 & 0.37 & 9.4 & 9.4 & 13.2 & 335.3 & 324.8 \\
\hline 400 & Maximum & 0.85 & 21.6 & 16.9 & 0.52 & 13.2 & - & 17.4 & 442.0 & 453.6 \\
\hline
\end{tabular}

supposedly both pit and spun cast iron given the installation dates that were provided, with a few pipes made of ductile iron and one made of steel.

Eighty-four samples underwent a complete set of tests on both pipe material (geometrical initial assessment) and soil samples, 16 underwent the pipe initial assessment only since no soil sample had accompanied them, and 14 were only soil samples and were tested as such. As well, 50 pipes had their tensile properties evaluated through tensile coupon tests and 10 of these were subjected to ring bearing tests as well.

\section{Geometrical evaluation}

The results of the geometrical evaluation are presented in Table 2 and are compared with specified values from ASA A21.6, ASA A21.8 (1962) and ASA A21.51 (1965). With respect to the average outside diameter, out of the eight $100 \mathrm{~mm}$ pipes, three had smaller diameters than specified, whilst the $150 \mathrm{~mm}$ pipes (71 samples) ranged somewhat symmetrically around the specified value. With one exception, the eight $200 \mathrm{~mm}$ pipes were greater in size than the value prescribed. The $300 \mathrm{~mm}$ pipes were centred around the specified value, with five samples having a smaller diameter, and the other five being larger. Finally, each of the 250, 350, and $400 \mathrm{~mm}$ diameter pipe samples that was measured had a diameter close to the values cited in the appropriate standard specifications. The above-mentioned standards do not explicitly specify tolerances for diameters.

Beside the ranges of specified pipe wall thickness values for each pipe diameter group, there also are minus tolerances imposed which restrict the pipe wall thickness to be not smaller than the prescribed value by more than $1.3 \mathrm{~mm}(100$, 150 , and $200 \mathrm{~mm}$ diameter pipes), $1.5 \mathrm{~mm}$ (250 and $300 \mathrm{~mm}$ diameter pipes), and $2.0 \mathrm{~mm}$ (350 and $400 \mathrm{~mm}$ diameter pipes); however, an additional minus tolerance of $0.5 \mathrm{~mm}$ is permitted over areas not to exceed $200 \mathrm{~mm}$ in any direction, only for grey cast iron pipes. No maximum tolerance is specified for any type of pipe.
All grey cast iron pipes had an average wall thickness within the minimum specified tolerances, although ten pipes, belonging to the 100 and $150 \mathrm{~mm}$ diameter groups, had larger wall thickness than the maximum limit. Given that ASA A21.6 and ASA A21.8 (1962) both refer to centrifugally cast iron pipes, it is hence probable that, at least for the pipes having a larger than maximum specified thickness, they may be older pipes manufactured using the pit casting technology. Indeed, those ones for which data were provided by the City were all manufactured before 1925, some of them being even older than 100 years, hence they were likely pit cast.

The thickness values of the 150 and $300 \mathrm{~mm}$ ductile iron pipes also fell within the applicable thickness range. The single $200 \mathrm{~mm}$ ductile iron pipe sample showed a significantly smaller wall thickness $(7.6 \mathrm{~mm})$ than the minimum recommended value of $8.4 \mathrm{~mm}$. This amounts to an undersizing of $0.8 \mathrm{~mm}$, or about $10.5 \%$, which is still within the $1.3 \mathrm{~mm}$ tolerance that also applies to $200 \mathrm{~mm}$ pipes.

Since the $150 \mathrm{~mm}$ grey cast iron pipes constituted most of the samples, histograms of the diameter and thickness distributions for these pipes before sandblasting were plotted and are presented in Figs. 4 and 5, respectively. From Fig. 4, it can be seen that only 34 pipes had a diameter value close to the specified value of $175.3 \mathrm{~mm}$. Eight pipes had a smaller diameter, whilst 29 were larger.

In terms of pipe wall thickness, only nine pipe samples did not fall within the specified range of 9.7 to $13.2 \mathrm{~mm}$, which can be seen from Fig. 5. Two of these pipes showed a wall thickness that was less than the minimum value of $9.7 \mathrm{~mm}$, but were still within the acceptable tolerance range. The remaining (seven pipes) had a wall thickness greater than the upper limit of $13.2 \mathrm{~mm}$.

In conclusion, all pipes were manufactured in conformity with the specifications. Diameter values were at times different from prescribed values, and although there are no restrictive tolerances on the diameter (a larger one not being 
Fig. 4. Distribution of diameters for $150 \mathrm{~mm}$ cast iron pipes.

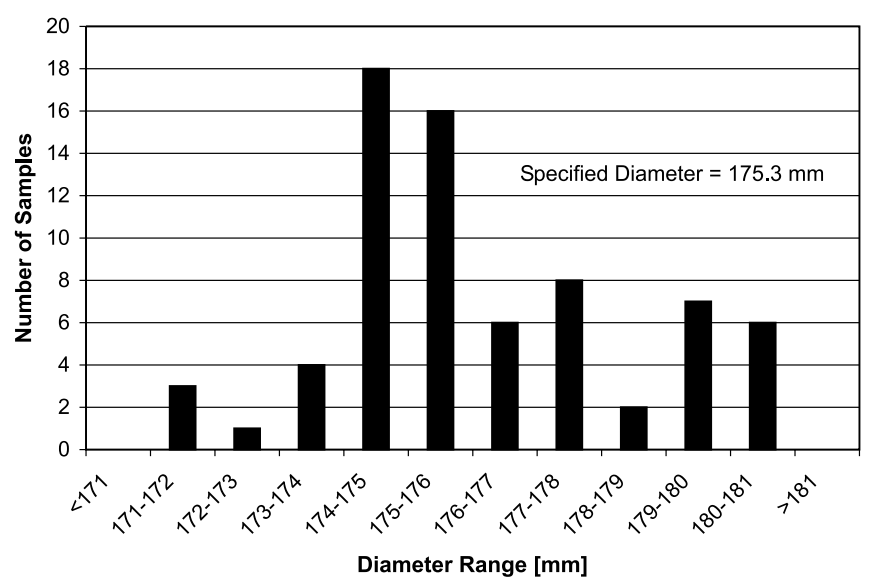

Fig. 5. Distribution of thickness values for $150 \mathrm{~mm}$ cast iron pipes.

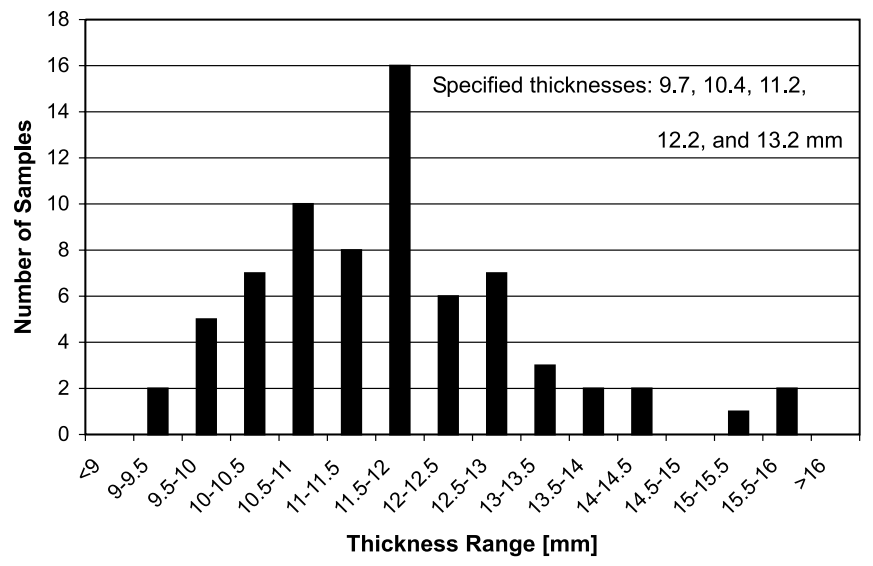

detrimental, whilst a smaller one could slightly restrict water flow), this shows that the quality control during the manufacturing process was not strict. All pipe wall thicknesses were within the minimum tolerance, with a few exceeding the upper range value. The latter can be deemed acceptable, since there is no upper tolerance limit imposed and it contributes to an increased mechanical strength of the pipes.

The sandblasting operation revealed the amount of metallic material remaining after corrosion. As was previously explained, heavily corroded pipes may have the appearance of intact material since the graphite network tends to maintain the original shape of the pipe. After this corrosion product has been removed, it is possible to evaluate the seriousness of the corrosion attack and an example of such a sandblasted corroded pipe ring is shown in Fig. 6.

The specimens were weighed after sandblasting in an attempt to approximately determine the amount of ferrous material lost to corrosion. It is recognized that the density of cast iron depends strongly on the carbon content. The different phases of iron have densities between 7860 and $7660 \mathrm{~kg} / \mathrm{m}^{3}$ whilst graphite has a density of $2250 \mathrm{~kg} / \mathrm{m}^{3}$ (GDIFS 1971). The density values for grey cast iron from the Iron Castings Handbook range from 6800 to $7400 \mathrm{~kg} / \mathrm{m}^{3}$ (GDIFS 1971), and an average value of $7100 \mathrm{~kg} / \mathrm{m}^{3}$ was used. This agrees reasonably with the value of $7210 \mathrm{~kg} / \mathrm{m}^{3}$ given in the Handbook of Steel Construction (CISC 2000).
Fig. 6. Sandblasted pipe ring seriously affected by corrosion.

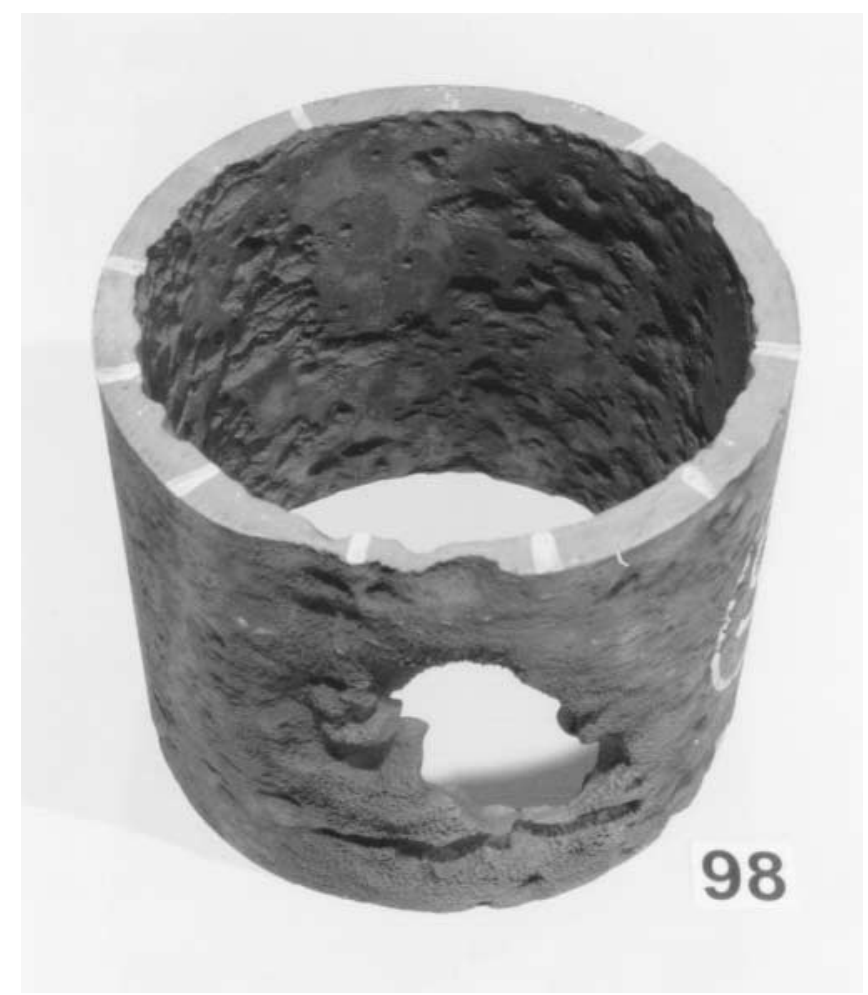

To achieve exact results, direct density measurements of each sample would have to be undertaken. However, for the purpose of this research, this increase in accuracy was not deemed to be warranted.

The loss of material, determined as explained above, varied from an insignificant $0.1 \%$ to $30.0 \%$, as can be seen in Fig. 7. Four pipes showed small amounts of material loss to corrosion (i.e., less than $5 \%$ by weight), 11 fell in the category of severely corroded pipes exhibiting more that $20 \%$ of material loss by weight, whilst the remaining 85 pipes suffered a moderate loss of material.

The median value of the material loss is higher for the case of the pipes that suffered mechanical breaks (namely $11 \%$ ) and even higher for those that failed as a result of corrosion breaks (namely 16\%), compared to the median value of those that did not break (namely 10\%). This suggests that the pipe structural strength is indeed affected by corrosion phenomena. As such, pipes that show small amounts of corrosion are not likely to experience breaks, whilst severely corroded pipes would likely fail because of corrosion breaks. If moderately corroded pipes experience increased mechanical loads at some point whilst in service, they would likely fail as a result of mechanical breaks. In other words, if two pipes were equally corroded, the one that would likely suffer a mechanical break would be the one experiencing the highest mechanical stress.

The relation between the amount of material loss for grey cast iron pipes, obtained through specimen weighing, and the age of the pipes (for the samples for which this information had been provided) is plotted in Fig. 8. It shows that many grey cast iron pipes that were older than 70 years experienced a major loss of material (only cast iron samples are included in this chart). For these older pipes, the trend is 
Fig. 7. Distribution of material loss from specimen weighing for all pipes.

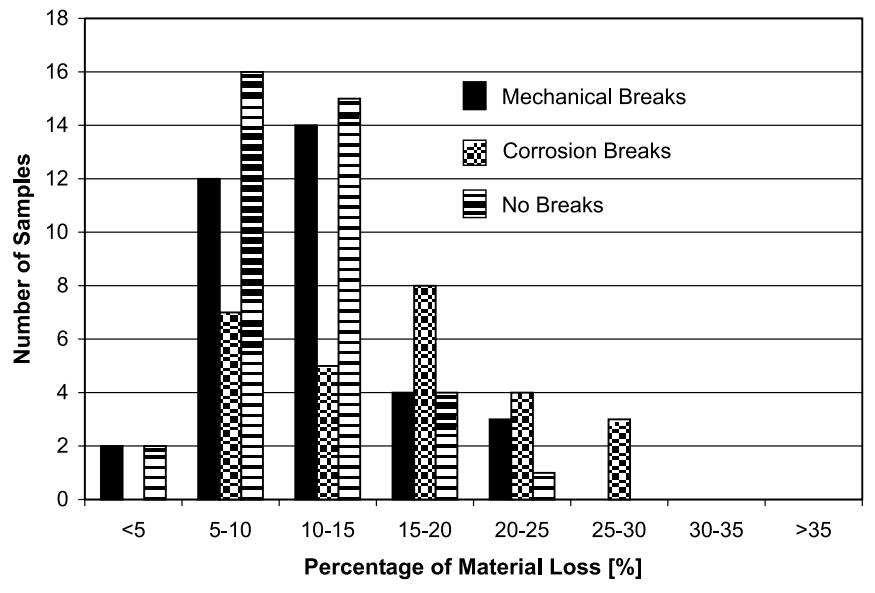

Fig. 8. Comparison between the amount of material loss from specimen weighing and the age of cast iron pipes.

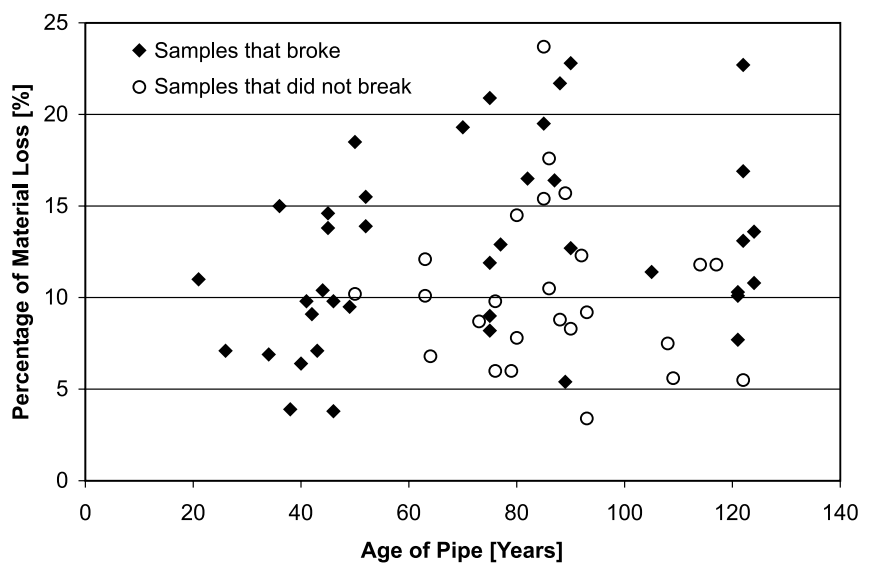

that the pipes that experienced breaks also showed a higher degree of material loss due to corrosion, whilst the ones that did not break were in a somewhat better state. Distinction is made between the samples that broke and those that did not break. The plot is characterized by three clusters, two of them corresponding to pipes installed about 85 and 125 years ago and mostly originating from the downtown core of the city of Toronto. It is likely that many water pipes were installed around these two time periods when the City was expanding. Further study of the data confirms that the older samples came largely from the downtown core of the City, whereas all of the younger samples originated from outside of the downtown area.

Pit depth measurements can be a very good indicator of the degree of pipe degradation due to corrosion and therefore were also performed on both the external and internal surfaces of the pipe rings. A "degree" of corrosion pit penetration was consequently obtained by dividing the maximum pit depth values (inside and outside) by the average pipe wall thickness for each ring surface. Then, the values corresponding to the internal surface of the sample were subtracted from those corresponding to the external surface. Hence, a "pit penetration balance index", which is an indica-
Fig. 9. Pit penetration balance index (*positive value, predominantly outside; negative value, predominantly inside).

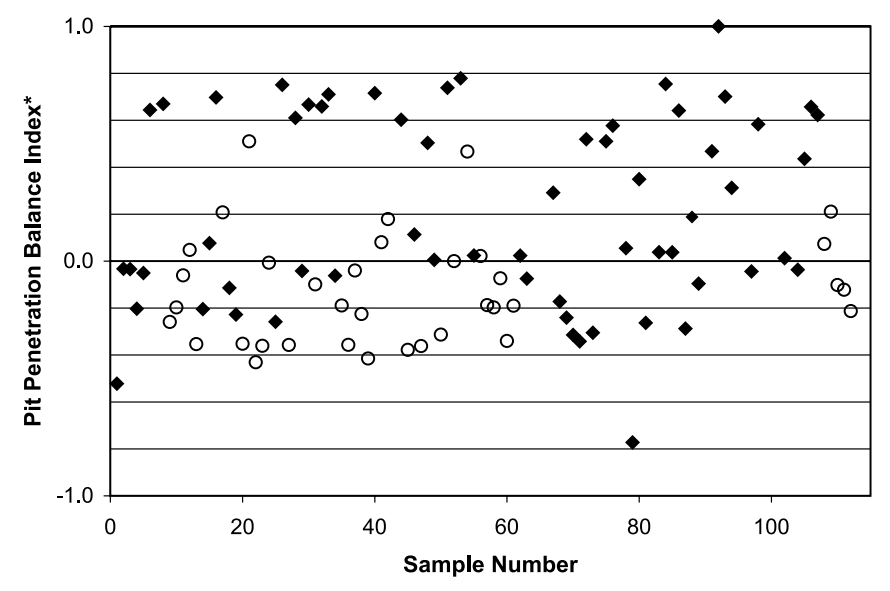

tor of the side of the pipe, external or internal, on which corrosion is predominant, was obtained. The results are shown in Fig. 9 (the same symbols apply for the samples that broke and those that did not break, as used in Fig. 8). A positive value of this index (the upper half of the plot) indicates that the pipe is more corroded on the outside than on the inside. An extreme case (i.e., a value of 1.0) indicates that a pipe was penetrated from the outside whilst experiencing no corrosion from the inside. Conversely, a negative value of the index indicates that a pipe suffered more corrosion damage on its internal surface than on the external one. This index shows that approximately half of the pipes were predominantly corroded on the outside with the other half showing more corrosion damage on the inside. Nevertheless, one can see that the predominantly externally corroded pipes show more scatter in the sense that some exhibited much more corrosion damage than their mostly internally corroded counterparts. Because the predominantly externally corroded pipes were more severely corroded, i.e., more weakened mechanically, they were also more likely to have suffered breaks, which can also be noticed from Fig. 9.

\section{Tensile tests}

A summary of the 50 tensile test results is presented in Table 3 and includes the net material stress at failure (i.e., the failure force divided by the net metallic area of the specimen at the section where fracture occurred) as the "material strength", the gross material stress at failure (i.e., the failure force divided by the total cross-sectional area of the specimen at the section where fracture occurred, including corrosion products (graphitization)) as the "residual strength", the loss of strength due to corrosion as a percentage difference between the two strengths, the initial tangent Young's modulus, and the secant modulus of elasticity at failure (i.e., corresponding to the maximum stress experienced).

For the ductile iron and steel specimens, which are printed in bold typeface (ID Nos. 48, 52, and 54), the strength values shown in Table 3 correspond to the ultimate strength, which is the maximum stress experienced, as opposed to the yield stress.

Some of the values of the Young's moduli are shown in parentheses. These values were considered as being unreli- 
Table 3. Mechanical properties from tensile tests.

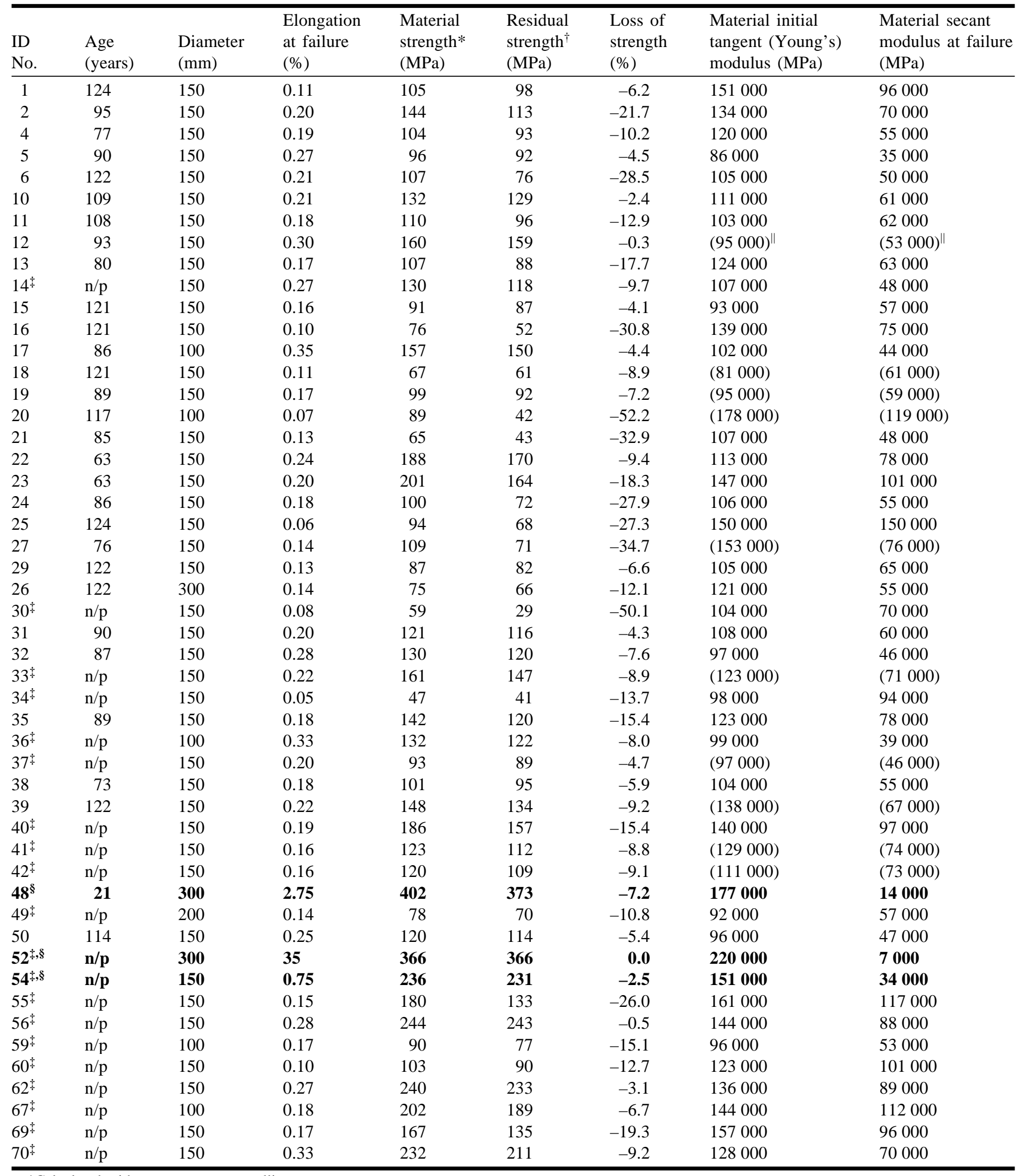

*Calculated with respect to net metallic area.

${ }^{\dagger}$ Calculated with respect to gross area.

${ }^{\ddagger}$ A Pipe and Soil Sample Field Report had not been received or no background data were provided by the City $(\mathrm{n} / \mathrm{p}=$ not provided).

${ }^{\S}$ The ultimate strength is represented for ductile iron and steel pipes (numbers in bold).

"The value of Young's modulus of elasticity shown in parentheses is not reliable because the specimen broke outside the gauge length. 
Fig. 10. Distribution of material tensile strength for the tested cast iron specimens.

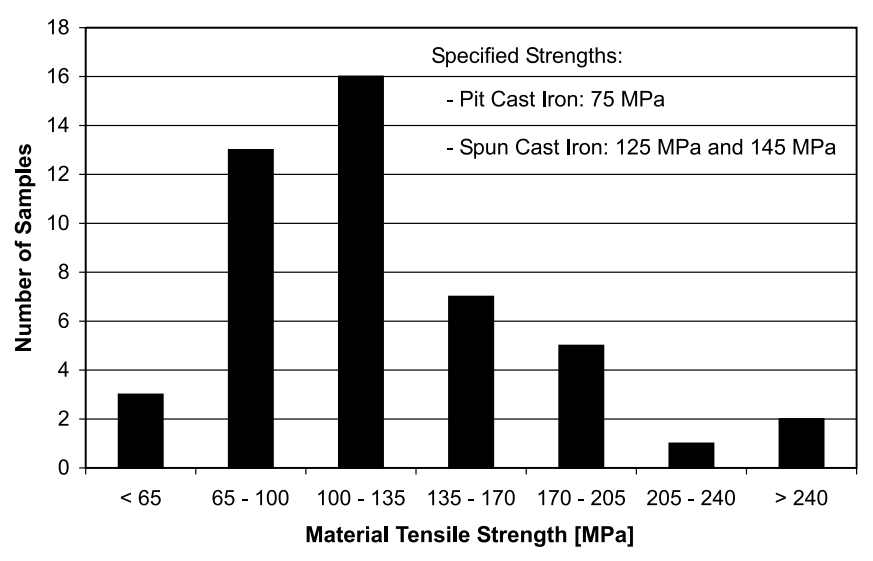

Fig. 11. Distribution of secant modulus of elasticity for the tested cast iron specimens.

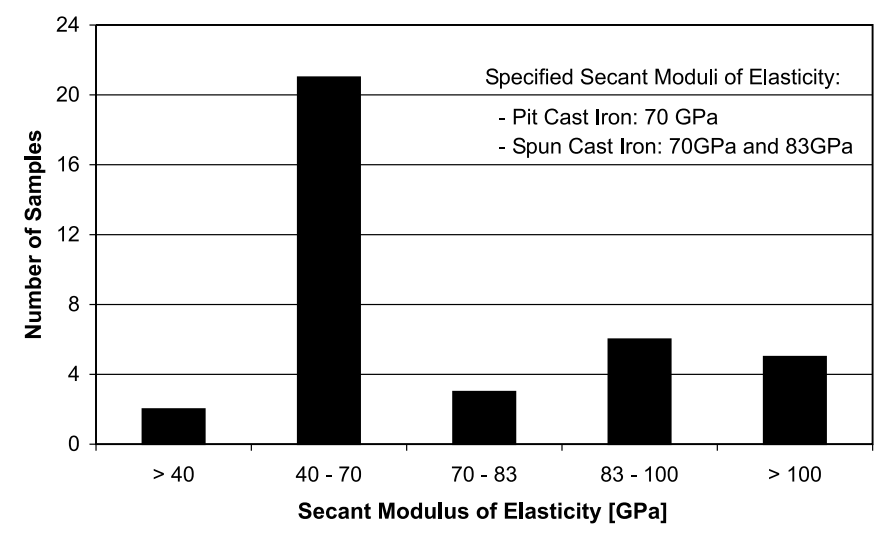

able because the tensile coupons fractured outside the gauge length, where the cross-sectional area was usually greater than that within the "dog-bone shape" region and hence the area and strain measurements were made in different sections.

The distribution of the values of the material tensile strength for the grey cast iron specimens is shown in Fig. 10. It can be seen that a majority of the samples fall into the three "bins", which encompass the standard specified values for tensile strength of 75,125 , and $145 \mathrm{MPa}$, corresponding to three different material grades (ASA21.1 1967), (ASA21.2, ASA21.6, and ASA21.8 1962). Nevertheless, three pipe samples showed a tensile strength lower than $65 \mathrm{MPa}$ and eight had strengths above $170 \mathrm{MPa}$.

Also important, for grey cast iron, is the distribution of the secant modulus of elasticity, which can be seen in Fig. 11. The secant modulus of elasticity, $E_{\mathrm{s}}$, is illustrated in Fig. 12. The specifications cite maximum values for this modulus as follows: $70000 \mathrm{MPa}$ for pit cast iron and spun cast iron pipes centrifugally cast in sand-lined moulds, and $83000 \mathrm{MPa}$ for the case of spun cast iron pipes centrifugally cast in metal moulds. It is indicated in the specifications that these maximum limits are not totally restrictive, provided that the modulus of rupture exceeds its own prescribed value in at least the same proportion. The plot shows that a major-
Fig. 12. Typical force/stress-strain plot for a tested grey cast iron tensile specimen.

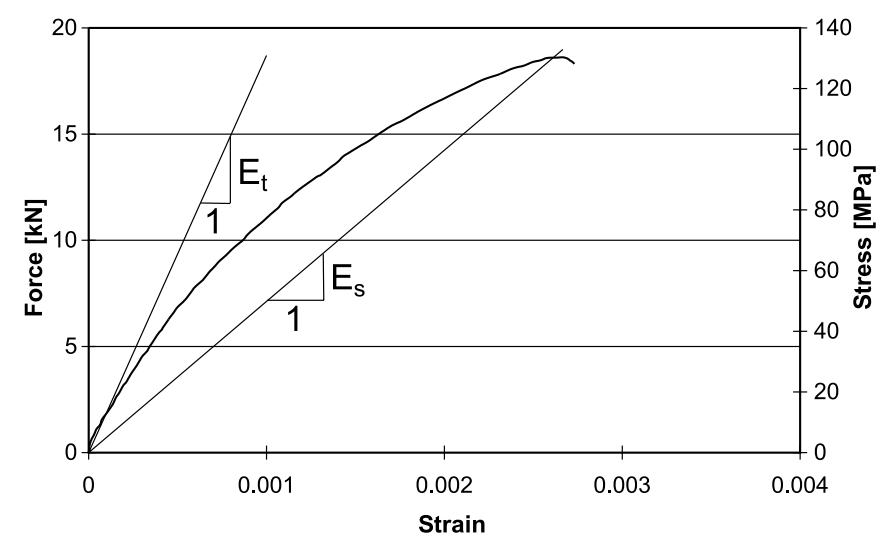

ity of specimens (26 samples) comply with the provisions of the standards, whilst only 11 pipe samples show higher values. This chart includes only the values of the moduli for the specimens that fractured within the gauge length during the tensile test; in other words, the values shown in parentheses in Table 3 were not taken into consideration.

Most of the cast iron force/stress-strain plots show a quasi-linear behaviour, with a linear segment corresponding to low values of the applied stress, which afterwards begins to curve, showing a certain mild excursion into the inelastic domain. The ratio between the two moduli of elasticity, the initial tangent modulus, $E_{\mathrm{t}}$, and the secant modulus, $E_{\mathrm{s}}$, is an indication of the deviation from the linear elastic behaviour of the material. A typical force/stress-strain plot for a grey cast iron specimen (ID No. 14) is shown in Fig. 12.

The tensile behaviour of one of the ductile iron specimens (ID No. 48), as well as of the steel pipe sample (ID No. 52) are shown in Figs. 13 and 14, respectively. Both the yield and the ultimate stress plateaus are shown on these charts. Since there was no obvious yield stress point on these curves (such as one would experience for hot-rolled mild structural steel), the yield stress was defined as the point from which, if the specimen were to be unloaded (following a slope similar to the initial tangent elastic modulus), a permanent plastic strain of $0.2 \%$ would occur. This is often termed the $0.2 \%$ offset method.

For ductile iron, ASA21.51 (1965) prescribes a minimum ultimate tensile strength of $415 \mathrm{MPa}$, a minimum yield strength of $290 \mathrm{MPa}$, a minimum Young's modulus of elasticity of $165000 \mathrm{MPa}$, and an elongation at failure greater than $10 \%$. Also, grade B pipe steel is prescribed as having a minimum ultimate strength of $415 \mathrm{MPa}$, a minimum yield stress of $240 \mathrm{MPa}$, and an elongation at failure (rupture of the specimen) of not less than 22\% (ASTM A53M-99b 1999). For illustrative purposes, grade 260 structural steel must exhibit a minimum ultimate tensile strength of $410 \mathrm{MPa}$ and a minimum yield stress of $260 \mathrm{MPa}$. The Young's modulus of elasticity must be $200000 \mathrm{MPa}$, and the elongation at failure has to be greater than $20 \%$ (CAN/CSAG40.20/G40.21-98).

The tensile strength and the secant modulus of elasticity exhibited a wide range of data scatter for cast iron pipes and this could be due to several factors. First, the tested coupons 
Fig. 13. Force/stress-strain plot of a tested ductile iron tensile specimen.

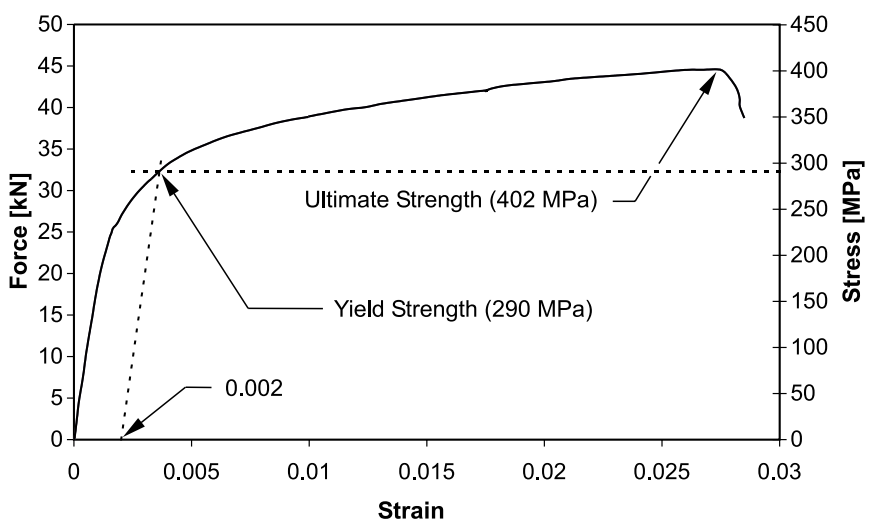

originated from pipe samples of different ages which were manufactured using different technologies. Second, as mentioned, the specified strengths are minimum values, with no tolerance ranges specified, and it is also likely that the pipes were produced by different manufacturers which employed different standards of quality at different times. Third, corrosion phenomena might have an intrinsic effect on the material tensile strength by microscopically affecting the interface between the affected and virgin material. This last aspect is not yet clear and needs further investigation.

Corrosion and other phenomena, however, have led to a loss of strength from the presumed initial strength through the loss of metallic material (the percentage difference between the pipe strength "as is" and its "effective" net metallic strength) and this varied from an insignificant value of $0.3 \%$ to an extreme of $52 \%$. The distribution of the loss of tensile strength due to corrosion is shown in Fig. 15. Most of the specimens (31 samples) showed a loss of tensile strength of less than $15 \%, 11$ of them exhibited a moderate loss falling between $15 \%$ and $30 \%$, whilst five samples showed a significant decrease of the tensile strength of more than $30 \%$. This shows that there is a dramatic decrease in strength for pipes that have lost metallic material to corrosion. However, further research is needed to investigate the impact of the lower tensile strength on the overall strength of pipes.

\section{Ring bearing tests}

The calculation of the modulus of rupture for the 10 tested samples is shown in Table 4. The geometrical dimensions that were used to determine the rupture modulus according to eq. [1] were those obtained from measuring the pipe before sandblasting, in the case of the length and diameter, and both before and after sandblasting in the case of the thickness. The values of the thickness were measured at the section where first fracture occurred in this test, as specified by the appropriate standards (ASA A21.6 and ASA A21.8 1962), and were averaged along the fracture surface. Two moduli were hence calculated: the apparent modulus based on the gross thickness, which includes the effects of corrosion, and the net metallic modulus for the net metallic pipe material. The strength loss was then calculated as the percentage dif-
Fig. 14. Force/stress-strain plot of a tested steel tensile specimen.

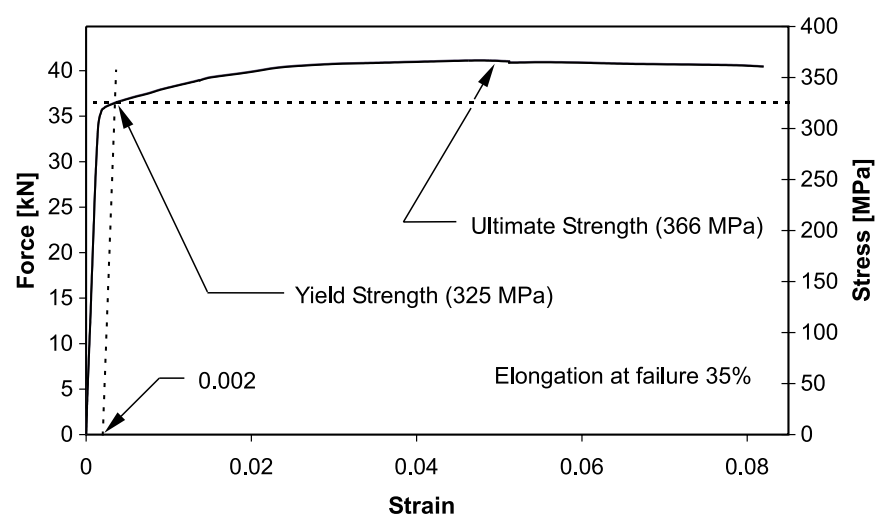

Fig. 15. Distribution of loss of strength (by tensile tests) for the tested cast iron specimens.

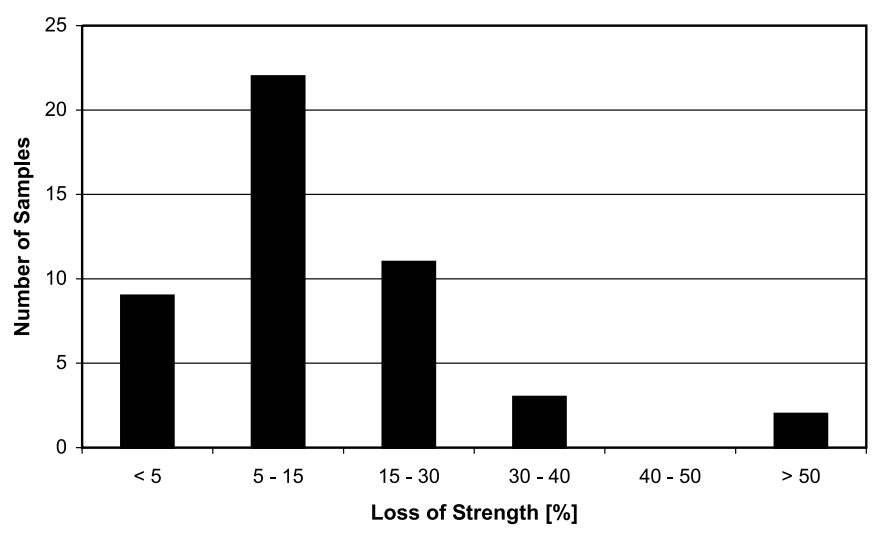

ference between the apparent modulus of rupture and the net modulus and ranged from $3 \%$ to $43 \%$.

The specifications mentioned above indicate minimum values for the modulus of rupture of $215 \mathrm{MPa}$ for pit cast iron pipes and either 275 or $310 \mathrm{MPa}$ for centrifugally cast iron pipes. Most of the pipes exhibited values of the net modulus of rupture (i.e., of the net metallic material) that were close to those given in the specifications and ranged from 199 to $305 \mathrm{MPa}$.

The cast iron pipe design standards also specify a pair of values for the tensile strength and the rupture modulus for each type of cast iron (namely, 75/215 MPa for pit cast iron, $125 / 275 \mathrm{MPa}$ and 145/310 MPa for spun cast iron). These values are plotted as hollow discs in Fig. 16. On the same plot, black rhombi correspond to the tensile strength and rupture modulus values obtained from testing the 10 pipe samples. Although the sample data size was small, a linear regression analysis was performed and a fitted trend line is also shown in the graph which relates the values of the tensile strength to the rupture modulus. Interestingly, the fitted line passes almost through the points corresponding to the standard specifications.

\section{Comparison of mechanical properties}

Mechanical properties of cast iron have been evaluated by several other researchers as well. Among them is Caproco Corrosion Prevention Ltd. of Edmonton (1985), which con- 
Table 4. Calculation of the modulus of rupture.

\begin{tabular}{|c|c|c|c|c|c|c|c|c|}
\hline $\begin{array}{l}\text { Pipe } \\
\text { No. }\end{array}$ & $\begin{array}{l}\text { External } \\
\text { diameter } \\
(\mathrm{mm})\end{array}$ & $\begin{array}{l}\text { Gross } \\
\text { thickness } \\
(\mathrm{mm})\end{array}$ & $\begin{array}{l}\text { Net metallic } \\
\text { thickness } \\
(\mathrm{mm})\end{array}$ & $\begin{array}{l}\text { Length } \\
(\mathrm{mm})\end{array}$ & $\begin{array}{l}\text { Failure } \\
\text { load } \\
(\mathrm{kN})\end{array}$ & $\begin{array}{l}\text { Modulus } \\
\text { of rupture } \\
(\mathrm{MPa})\end{array}$ & $\begin{array}{l}\text { Net } \\
\text { modulus } \\
\text { of rupture } \\
(\mathrm{MPa})\end{array}$ & $\begin{array}{l}\text { Strength } \\
\text { loss }(\%)\end{array}$ \\
\hline 1 & 177.3 & 10.9 & 9.6 & 152.1 & 22.4 & 197 & 256 & -23.0 \\
\hline 2 & 177.2 & 11.3 & 10.7 & 152.3 & 38.3 & 312 & 349 & -10.6 \\
\hline 4 & 179.8 & 13.9 & 13.4 & 152.7 & 41.7 & 224 & 241 & -7.0 \\
\hline 5 & 172.0 & 10.9 & 9.6 & 154.3 & 18.3 & 153 & 199 & -23.1 \\
\hline 6 & 175.9 & 9.7 & 7.4 & 152.2 & 8.5 & 94 & 164 & -42.7 \\
\hline 14 & 180.9 & 13.4 & 13.2 & 153.3 & 51.0 & 296 & 305 & -3.0 \\
\hline 15 & 175.7 & 11.0 & 10.4 & 153.5 & 24.0 & 203 & 228 & -11.0 \\
\hline 18 & 175.5 & 11.8 & 11.1 & 155.0 & 31.1 & 225 & 255 & -11.8 \\
\hline 19 & 175.0 & 11.9 & 11.1 & 154.1 & 33.1 & 236 & 273 & -13.6 \\
\hline $20 *$ & 129.4 & 13.2 & 11.6 & 156.8 & 52.6 & 213 & 280 & -23.9 \\
\hline
\end{tabular}

Fig. 16. Relationship between the tensile strength and rupture modulus.

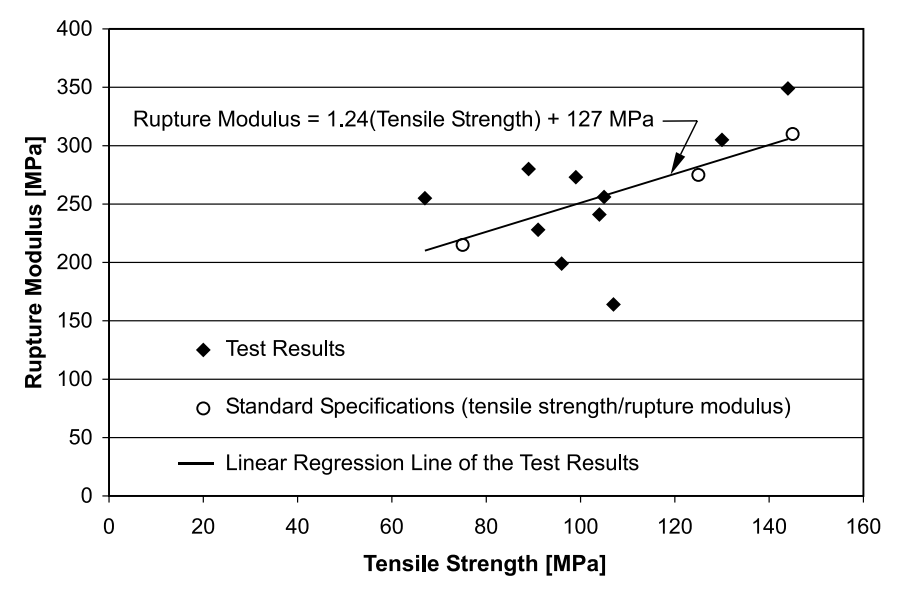

ducted mechanical tests on spun cast iron pipes sampled from the city of Calgary. Conlin and Baker (1991), in a more comprehensive study based on a fracture toughness approach, determined a tensile strength of cast iron water mains focusing mainly on the properties of cast iron as a material, without relating them to factors that may also influence the pipe strength such as production technologies, manufacturing defects, or the progressive growth of corrosion pits. More recently, Rajani et al. ${ }^{2}$ conducted tensile, ring, Talbot strip four-point bending, and fracture toughness tests on cast iron pipes that were supplied by 19 water utilities in Canada and in the United States, with diameters of 150 and $200 \mathrm{~mm}$. A summary of the mechanical properties obtained by these researchers together with data obtained from other studies and specifications prescribed in standards is presented in Table 5 .

These test data reveal that there are obvious differences between the mechanical properties of pit and spun cast iron pipe materials. As expected, the tensile strength, modulus of rupture, and fracture toughness are generally lower for pit cast iron than for spun cast iron; the secant moduli are, how- ever, not very different between the two types of pipes. Also, whilst tensile strength and fracture toughness could both be used to differentiate between the type of cast iron (pit cast or spun cast), it seems that the fracture toughness may be the slightly more consistent of the two, showing somewhat less scatter of data.

\section{Soil tests}

Ninety-eight tests were performed on soils and the results obtained show that they ranged from sand-like, cohesionless soils to high plasticity clayey soils. Many of them exhibited an intense reaction with hydrochloric acid, $\mathrm{HCl}$, which denoted the presence of salts, such as carbonates, in large amounts. In general, no specific organic smell was detected for most of them; nevertheless, it is to be underlined that eight of the samples that exhibited an obvious organic odour also showed a substantially increased level of sulphide concentration, which suggests that higher levels of the latter can probably be in fact detected via the unmistakable rotten-egg smell.

Tests have revealed resistivity values ranging from the highest value of $22600 \Omega \cdot \mathrm{cm}$ to values as low as $36.2 \Omega \cdot \mathrm{cm}$. (The latter corresponded to the only sample that, during the test, exhibited a strong, bubbling, electrolysis phenomenon suggesting that an extremely large concentration of salt ions was present.)

The distribution of the measured resistivity values is shown in Fig. 17. The ranges of the "bins" were chosen in a manner such that they matched those from Table 1 that characterized the corrosion potential of soil as a function of resistivity. In conjunction with this table, one can see that a majority of the samples fell in the $1000-3000 \Omega \cdot \mathrm{cm}$ category, which suggests a strong aggressive corrosion capability, whilst the others were evenly distributed amongst the remaining ranges. Of the latter, 14 samples had resistivity values between 500 and $1000 \Omega \cdot \mathrm{cm}$, therefore placing them in the very strongly aggressive soil category, and 11 showed values of less than $500 \Omega \cdot \mathrm{cm}$, which would characterize the originating soil as being extremely aggressive.

\footnotetext{
${ }^{2}$ Rajani, B., Makar, J.M., and McDonald, S. The mechanical properties of grey cast iron water mains. Submitted to ASCE Journal of Materials in Civil Engineering.
} 
Table 5. Comparison of mechanical properties of cast iron pipes (adapted from Rajani et al..$^{\dagger}$ ).

\begin{tabular}{|c|c|c|c|c|c|c|}
\hline $\begin{array}{l}\text { Type of cast } \\
\text { iron }\end{array}$ & Reference & Specification/feature & $\begin{array}{l}\text { Tensile } \\
\text { strength } \\
(\mathrm{MPa})\end{array}$ & $\begin{array}{l}\text { Modulus } \\
\text { of rupture } \\
(\mathrm{MPa})\end{array}$ & $\begin{array}{l}\text { Secant elastic } \\
\text { modulus }(\mathrm{MPa})\end{array}$ & $\begin{array}{l}\text { Fracture } \\
\text { toughness } \\
(\mathrm{MPa} \sqrt{\mathrm{m}})\end{array}$ \\
\hline Pit & Rajani et al..$^{\dagger}$ & Age: $66-120$ years & $33-267$ & $132-378$ & $38000-168000$ & $5.7-13.7$ \\
\hline Pit and spun & Yamamoto et al. (1983) & Age: $22-79$ years & $100-150$ & $20-250$ & na & na \\
\hline Pit and spun & Caproco Corrosion (1985) & Age: $22-28$ years & $70-217$ & na & na & na \\
\hline Spun & ASA A21.6 (AWWA C106) (1962) & 1953-1982 & 125 & 275 & 83000 & na \\
\hline Spun & ASA A21.8 (AWWA C108) (1962) & 1953-1982 & 125 & 275 & 70000 & na \\
\hline Spun & ASA A21.1 (AWWA H1) (1967) & $1967-1982$ & 145 & 310 & 93000 & na \\
\hline Spun & Rajani et al. ${ }^{\dagger}$ & Age: $28-73$ years & $135-305$ & $194-445$ & $43000-159000$ & $10.3-15.4$ \\
\hline
\end{tabular}

*Where data were available.

${ }^{\dagger}$ Rajani, B., Makar, J.M., and McDonald, S. The mechanical properties of grey cast iron water mains. Submitted to ASCE Journal of Materials in Civil Engineering.

Fig. 17. Distribution of resistivity values.

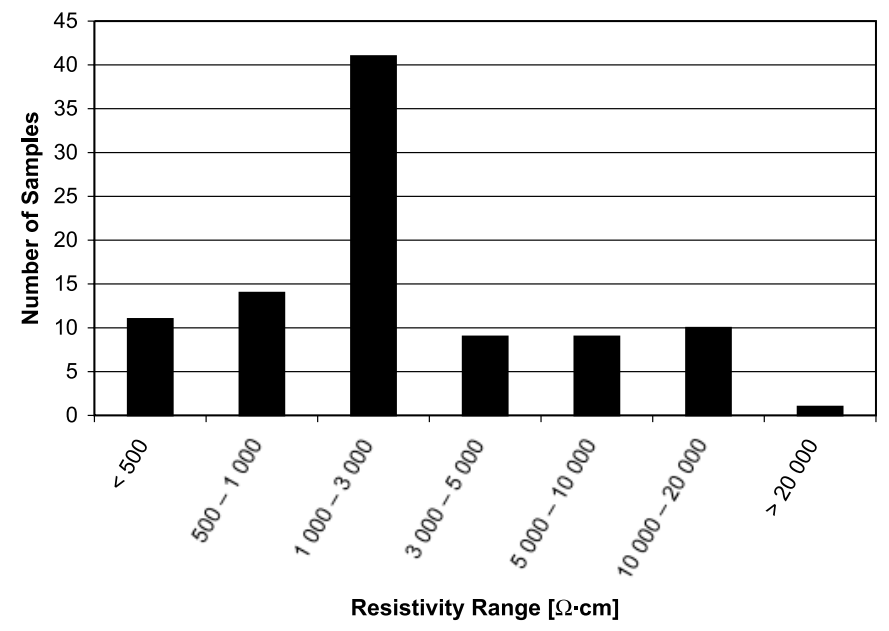

Measurements of $\mathrm{pH}$ indicated that all soils were alkaline in nature, thus eliminating the possibility of containing strong acids that could attack the pipe metal. Nevertheless, a basic environment could also create favourable conditions for the different kinds of anaerobic bacteria to thrive, hence providing suitable conditions for microbiological corrosion to occur. The $\mathrm{pH}$ values ranged from a near-to-neutral value of 7.2 to a medium alkaline 10.5, therefore offering most of the samples almost ideal conditions for anaerobic bacteria to grow (i.e., an alkaline medium).

The distribution of the sulphide concentration in the soil samples tested is presented in Fig. 18. It is generally considered that sulphide concentrations lower than $5 \mathrm{mg} / \mathrm{kg}$ of dry soil would render the soil as being not aggressive, higher than $10 \mathrm{mg} / \mathrm{kg}$ of dry soil would be an indication of a highly corrosive potential, whilst values in between would characterize soils that exhibit moderate corrosiveness. In the present case, a majority of the tested samples, namely 93 samples, showed concentrations less than $5 \mathrm{mg} / \mathrm{kg}$ of dry soil, therefore emphasizing that microbiological corrosion would not be a significant issue at the locations where these samples had been taken from. Six samples could be characterized as being moderately corrosive, whilst five of those
Fig. 18. Distribution of sulphide concentration.

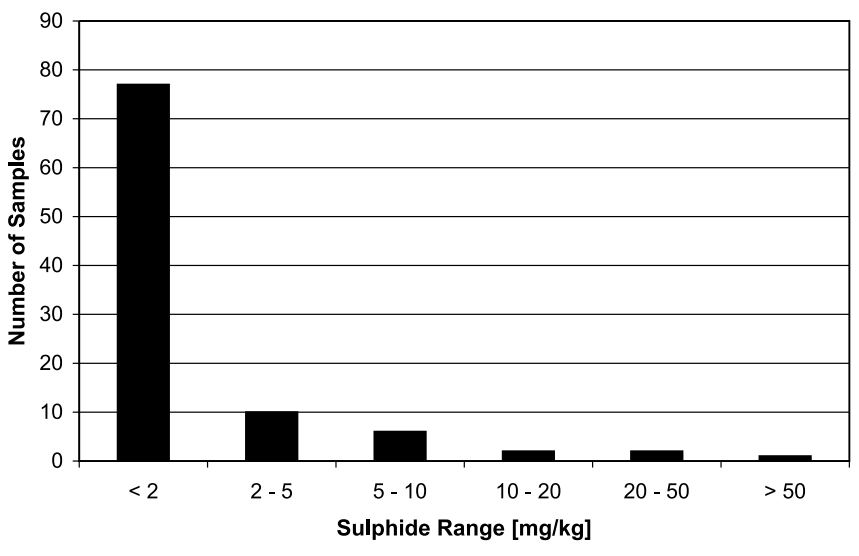

could be corrosive since their concentrations were in excess of $10 \mathrm{mg} / \mathrm{kg}$.

The relationship between the two main corrosion potential indicators, namely soil resistivity and sulphide concentration, and the observed degree of corrosion can be assessed by comparing the average corrosion pitting rate with the same soil characteristics. The average pitting rate was calculated by dividing the maximum external pit depth to the age of the water main, even though the corrosion phenomena cannot be described as a linear function with time (Rajani and Makar 2000). Also, the distribution of pipe age was broad, ranging from 21 to 124 years, with 29 pipes being younger than 50 years, 36 being between 51 and 100 years old, and 15 pipes being older than 100 years.

Therefore, Fig. 19 shows the correlation between the average pitting rate and the measured values of the resistivity for the pipe samples for which the age was provided. (The two ductile iron samples are also included, but not the steel sample for which no soil sample was received.) The plot shows that higher average pitting rates are observed in soil with low resistivity and that soil resistivity has a significant impact on corrosion of pipes. One can see that as soon as the resistivity values become less than $2000 \Omega \cdot \mathrm{cm}$, for which the soil is said to be strongly aggressive (Table 1), the pitting rate generally begins to increase rapidly. The isolated point 
Fig. 19. Relationship between the pitting rate and resistivity (for cast iron and two ductile iron pipes).

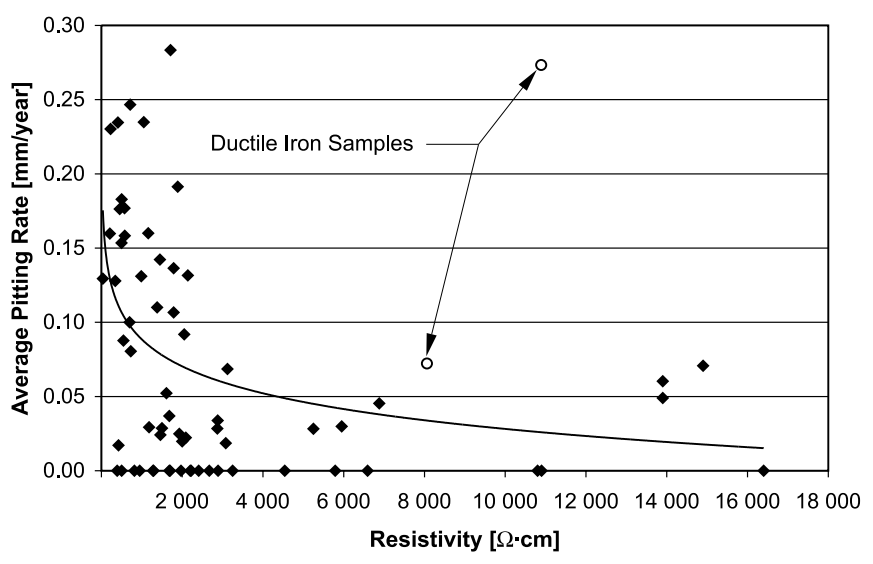

that shows an average corrosion pitting rate of about $0.27 \mathrm{~mm} /$ year belongs to a ductile iron pipe sample, which is characterized by a different corrosion behaviour from grey cast iron pipe. A best-fit line for these data is a logarithmic line that renders an $R^{2}$ value of 0.3 (excluding the abovementioned ductile iron), which does not, however, indicate a strong correlation.

\section{Conclusions}

To develop and implement plans of action and priority schemes aimed at minimizing the number and cost of failure events, three conditions must be fully assessed and understood: $(i)$ the state of deterioration of the system; (ii) the mechanisms by which the system fails (a loss of structural integrity, usually accompanied by reduced hydraulic efficiency and ability to preserve water quality); and (iii) the identification of the network sections that require service in the form of repair or rehabilitation (which should ideally take place before any failures occur).

As an important step towards achieving this objective, this paper has presented an evaluation of the properties of grey cast iron, ductile iron, and steel water mains and soil samples as part of a 3-year research project with the City of Toronto. One hundred samples were analysed to determine the state of degradation and the mechanical properties of the pipe samples, whilst the corrosion potential of the soil samples was assessed with respect to the soil-pipe material interaction.

From the samples investigated, perhaps the most important conclusion is that the condition of parts of the City of Toronto water main system is in a fairly advanced state of wear. Geometrical assessment of the pipes has shown that over $95 \%$ of the samples, whether having sustained breaks or not, suffered moderate to severe corrosion damage. Measures to stop, or at least to retard, the corrosion process for these pipe segments are hence recommended. The chosen measures would depend on several factors, including the amount of material loss to corrosion, as in certain severe situations a replacement solution may prove more reliable and cost effective than a rehabilitation process. If, for instance, the internal degree of corrosion is not severe, the degradation phenomenon can be halted by cleaning and lining the pipe using conventional cement-mortar lining material or employing other innovative trenchless technology materials such as cured-in-place plastic liners or CIPP liners.

Mechanical testing has shown that the strength of both grey cast iron and ductile iron pipes can be dramatically influenced by corrosion phenomena. Although a majority of the samples showed a net metallic tensile strength in compliance with the applicable standard provisions, corrosion pits, depending on their size, can affect the strength of the pipe material by acting as stress concentrators and crack initiators. Strength can also be influenced by manufacturing defects, the obvious observed type being the presence of air inclusions, which seemed to occur rather commonly in older pipes, and by the manufacturing technology that was used for specific pipes at specific times.

Lastly, soil testing has indicated that although most of the City of Toronto territory was not characterized by a presence of aggressive soils, there were some areas that possessed a higher corrosion potential. Once identified, the pipe segments that pass through such soils ought to be further protected against external corrosion, such as by cathodic protection. Despite the 98 tested soil samples, which at first glance may seem to represent a large number, only a few areas of the city of Toronto were in fact represented. Therefore, more soil samples should be analysed with samples obtained uniformly across the City.

Several failure modes were identified with preponderance, amongst them being circumferential cracks, longitudinal cracks, and blown-out holes. To better understand the reason for the occurrence of each of these failure modes, further experimental and theoretical investigations ought to be performed with respect to the structural strength of corroded pipes and the loads that act on them.

An important benefit of this study is that it provides a starting point for future research by establishing a platform that can act as a basis for more comprehensive assessments of the state of the water main network of the City of Toronto and of water utilities in other cities that are confronted with increased rates of failure. Comprehensive data bases containing pertinent information about each specific network (ranging from historical background data and pipe failure information to mechanical properties of the pipe material and a distribution of the soil properties across the region) can be built into Geographical Information System (GIS) multi-layered maps. One such undertaking is currently being taken by the National Research Council of Canada, Ottawa (Rajani 2000). Other developments may also include, besides the evaluation of future failure data, analytical and numerical studies to provide soil loading models and structural resistance models for deteriorated pipes. On the basis of this knowledge, the state of degradation of each water main could be assessed and its reliability could be predicted. Hence, water utilities would be provided with an invaluable tool for their infrastructure asset management.

\section{Acknowledgements}

Financial support for this project has been provided by the City of Toronto, under the supervision of Mr. T. Dennis, Mr. W. Green, and Mr. M. D'Andrea, as well as by the Natural Sciences and Engineering Research Council of Canada (NSERC). The authors are grateful to Dr. J. Makar and 
Dr. B. Rajani from the National Research Council of Canada, Ottawa, for providing advice and sharing their vast experience gained from dealing with water main system problems experienced by water utilities across North America. The collaboration of Professor B. Karney and laboratory assistance of Mr. G. Doyle and Mr. R. Yee are also gratefully acknowledged. The authors would also like to thank Mr. K. Sarrami and Ms. I. Tarvydas from the City of Toronto for their assistance when site sampling problems arose and for providing valuable pipe historical information.

\section{References}

ASA A21.1 (AWWA H1). 1967. U.S.A. standard for thickness design of cast-iron pipe. American Water Works Association, New York, N.Y.

ASA A21.2 (AWWA C102). 1962. American standard for cast-iron pipe, pit-cast, for water or other liquids. American Water Works Association, New York, N.Y.

ASA A21.6 (AWWA C106). 1962. American standard for cast-iron pipe, centrifugally cast in metal molds, for water or other liquids. American Water Works Association, New York, N.Y.

ASA A21.8 (AWWA C108). 1962. American standard for cast-iron pipe, centrifugally cast in sand-lined molds, for water or other liquids. American Water Works Association, New York, N.Y.

ASA A21.51 (AWWA C151). 1965. American standard for ductileiron pipe, centrifugally cast in metal molds or sand-lined molds, for water or other liquids. American Water Works Association, New York, N.Y.

ASTM A53M-99b. 1999. Standard specification for pipe, steel, black and hot-dipped, zinc-coated, welded and seamless. American Society for Testing and Materials, West Conshohocken, Pa.

ASTM D2488-93. 1993. Standard practice for description and identification of soils (visual-manual procedure). American Society for Testing and Materials, New York, N.Y.

ASTM E8-94a. 1994. Standard test methods for tension testing of metallic materials. American Society for Testing and Materials, New York, N.Y.

ASTM G46-94. 1994. Standard guide for examination and evaluation of pitting corrosion. American Society for Testing and Materials, New York, N.Y.

ASTM G51-95. 1995. Standard test method for measuring $\mathrm{pH}$ of soil for use in corrosion testing. American Society for Testing and Materials, New York, N.Y.

ASTM G57-95a. 1995. Standard test method for field measurement of soil resistivity using the Wenner four-electrode method. American Society for Testing and Materials, New York, N.Y.

CAN/CSA-G40.20/G40.21-98. 1998. General requirements for rolled or welded structural quality steel. Canadian Standards Association, Toronto, Ont.

Caproco Corrosion Prevention Ltd. 1985. Underground corrosion of water pipes in Canadian cities. Case: The city of Calgary. Report prepared for CANMET, Ottawa, Ont.

CISC. 2000. Handbook of steel construction. 7th ed. 2nd revised printing. Canadian Institute of Steel Construction, Toronto, Ont., pp. 7-40.

Conlin, R.M., and Baker, T.J. 1991. Application of fracture mechanics to the failure behaviour of buried cast iron mains. Transport and Road Research Laboratory, London, England. Contract Report 266.

Crawford, R. 1996. Municipal sewage and water systems are in a state of crisis. Environmental Science and Engineering, September, 9: 30 .
Davey, T. 1997. The pipes, the pipes are appalling. Environmental Science and Engineering, March, 10: 9.

Dennis, T. 1998. The City of Toronto experience. Presentation at a rehabilitation workshop, Centre for Advancement of Trenchless Technologies, University of Waterloo, 4 March 1998, Waterloo, Ont.

ES\&E. 1997. Ontario will transfer all water and sewage works to municipalities. Environmental Science and Engineering, March, 10: 77.

GDIFS. 1971. Gray and ductile iron castings handbook. Gray and Ductile Iron Founders' Society, Cleveland, Ohio.

Hertzler, P.C., and Davies, C. 1997. The cost of infrastructure needs. Journal of the American Water Works Association, 89: $55-61$.

Karney, B. 1996. Hydraulic analysis of leaking water distribution systems. Uni-Bell PVC Pipe News, 19(1): 8-11.

Keeling, D. 1996. New techniques for the reduction of unaccounted-for water. Environmental Science and Engineering, September, 4: 52-54.

McGhee, T.J. 1991. Water supply and sewerage. 6th ed. McGrawHill, New York, N.Y.

METALogic. 1998. http://www.metalogic.be/. METALogic N.V., Heverlee, Belgium.

Rajani, B. 2000. New software will help municipalities plan for water main renewal. Construction Innovation, National Research Council of Canada, Ottawa, Ont., 5(4): 9.

Rajani, B., and Makar, J.M. 2000. A methodology to estimate remaining service life of grey cast iron water mains. Canadian Journal of Civil Engineering, 27: 1259-1272.

Rajani, B., Makar, J.M., McDonald, S., Zhan, C., Kuraoka, S., Jen, C-K., and Viens, M. 2000. Investigation of grey cast iron water mains to develop a methodology for estimating service life. Report to American Water Works Association Research Foundation, Denver, Colo.

Seica, M.V., Packer, J.A., Grabinsky, M.W.F., Adams, B.J., and Karney, B.W. 2000. Evaluation and testing of cast iron and ductile iron water main samples. Final Report to the City of Toronto, University of Toronto, Toronto, Ont., ISBN 0-7727-7551-6.

Yamamoto, K., Mizoguti, S., and Yoshimitsu, K. 1983. Relation between graphitic corrosion and strength degradation of cast iron pipe. Corrosion Engineering, 32: 157.

\section{List of symbols}

$a$ inner electrode spacing measured from the inner edge of the electrode pins $(\mathrm{cm})$

$A$ cross-sectional area of the container, perpendicular to the current flow $\left(\mathrm{cm}^{2}\right)$

$b$ length of the ring $(\mathrm{mm})$

$d$ average inside diameter $(\mathrm{mm})$

$I$ current drawn from the source (A)

ppm parts per million measured sulphide using a Gastec safety tube (ppm)

$S^{2-}$ concentration of sulphide in dry mass of soil $(\mathrm{mg} / \mathrm{kg})$

$R$ rupture modulus (MPa)

$t$ average thickness of the pipe along the principal line of fracture $(\mathrm{mm})$

$U$ voltage drop between the inner electrodes (V)

$w$ moisture content of soil (\%)

$W$ breaking load $(\mathrm{kN})$

$\rho$ soil resistivity $(\Omega \cdot \mathrm{cm})$ 